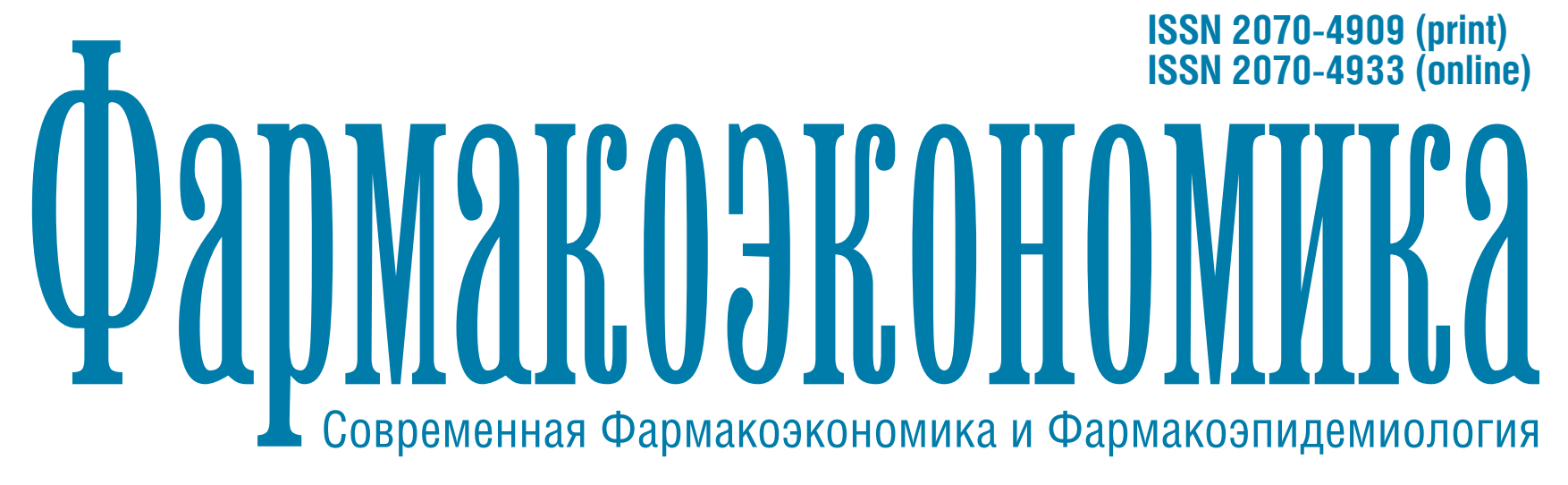

ISSN 2070-4909 (print)

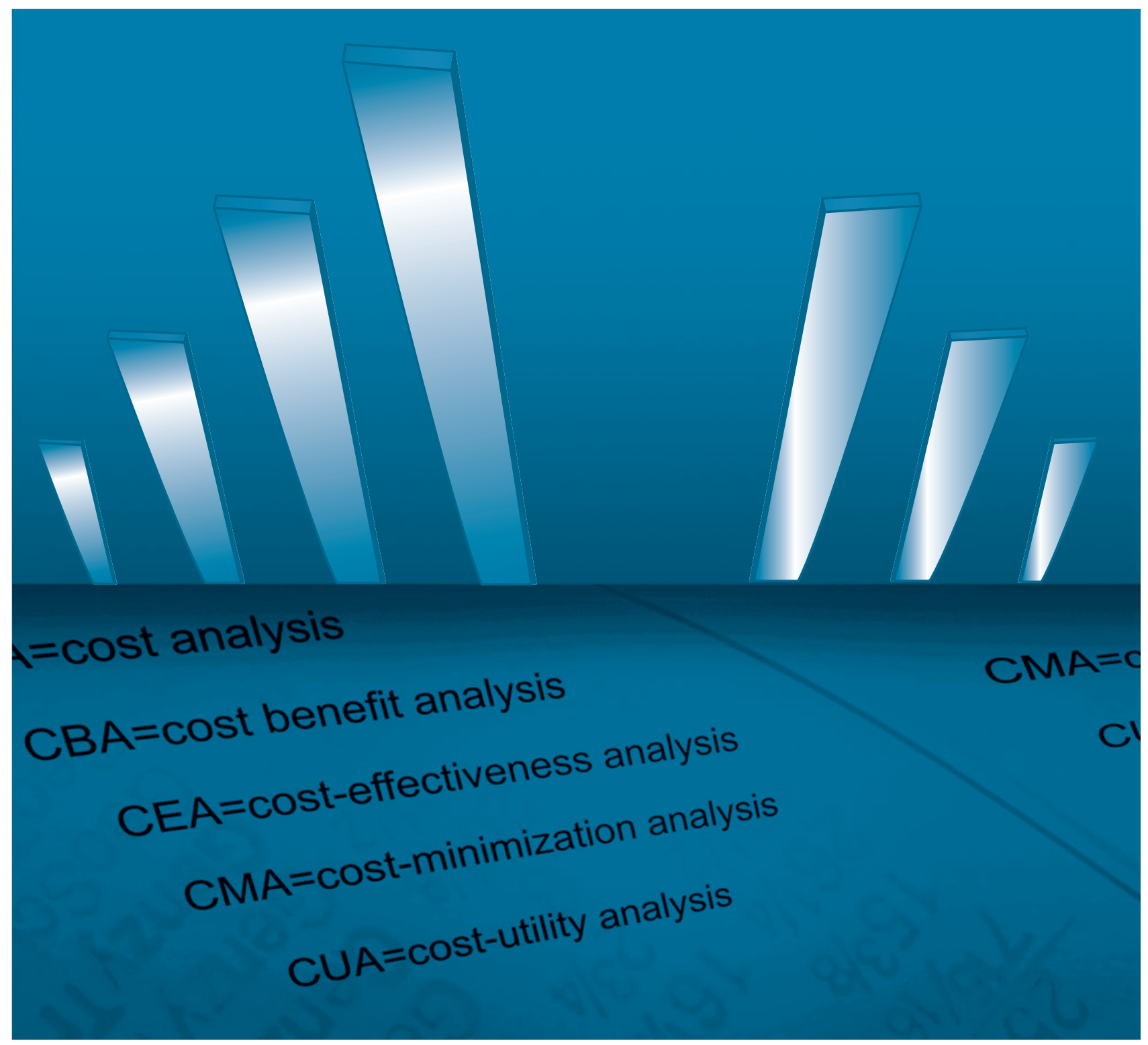

FARMAKOEKONOMIKA

Modern Pharmacoeconomic and Pharmacoepidemiology 2020 Vol. 13 No2

www.pharmacoeconomics.ru

- Доступность генной терапии in vivo. Проблемы и решения

- Концепция ценностно-ориентированного здравоохранения

- Стоит ли переосмыслить полученный полвека назад положительный опыт применения хондроитинсульфатов при атеросклерозе?

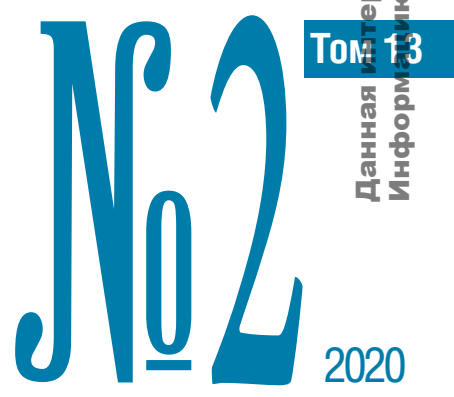


РЕЗЮМЕ

Введение. Пандемия COVID-19 выявила уязвимость широких слоев населения к этому инфекционному заболеванию, определяющуюся отсутствием иммунитета к новому коронавирусу SARS-CoV-2 и цитокиновым штормом при тяжелом течении. Одной из важнейших причин этой уязвимости является широчайшее распространение микронутриентных дефицитов и, прежде всего, десрицита витамина D. Цель. Систематизировать доступные данные о роли витамина D в профилактике инфекции COVID-19.

Материалы и методы. Систематический компьютерный анализ всего массива публикаций имеющейся научной литературы по коронавирусам (21300 публикаций в PUBMED и репозиториям препринтов, в т.ч. 7500 публикаций по COVID-19 и SARS-CoV-2). Использованы методы топологического и метрического анализа данных. Выделены около 50 наиболее информативных рубрик, ассоциированных преимущественно с COVID-19/SARS-CoV-2. Выполнен анализ полученной «карты» молекулярной патофизиологии COVID-19.

Результаты. Витамин D активирует экспрессию многих генов, вовлеченных в поддержку иммунитета против коронавирусов и других одноцепочечных РНК-вирусов (интерферон-зависимая защита). Результаты систематического анализа текстов публикаций по коронавирусам показали, что витамин D важен для ослабления эфрфектов цитокинового шторма и для компенсации хронических коморбидных патологий.

Заключение. Таким образом, компенсация недостаточности витамина D - необходимая составляющая просилактики COVID-19. Oказываясь менее затратной, чем ведение пациентов с тяжелым течением COVID-19, данная тактика может способствовать экономии ресурсов здравоохранения.

КЛЮЧЕВЫЕ СЛОВА

COVID-19, PHK-вирусы, микронутриенты, холекальциферол, Аквадетрим, Спрейдетрим.

Статья поступила: 14.05 .2019 г.; в доработанном виде: 02.06.2020 г.; принята к печати: 15.06 .2020 г.

\section{Консликт интересов}

Авторы заявляют об отсутствии необходимости раскрытия финансовой поддержки или конфлликта интересов в отношении данной публикации. Все авторы сделали эквивалентный вклад в подготовку публикации.

\section{Финансирование}

Работа выполнена по грантам РФФИ № 19-07-00356 и 18-07-00944.

\section{Для цитирования}

Громова О. А., Торшин И. Ю., Габдулина Г.Х. Пандемия COVID-19: защитные роли витамина D. ФАРМАКОЭКОНОМИКА. Современная Фармакоэкономика и Фармакоэпидемиология. 2020; 13 (2): 132-145. https://doi.org/10.17749/2070-4909/farmakoekonomika.2020.044.

\section{COVID-19 pandemic: protective role of vitamin D}

Gromova 0. A. ${ }^{1,2}$, Torshin I. Yu. ${ }^{1,2}$, Gabdulina G. Kh. ${ }^{3}$

${ }^{1}$ V.A. Nasonov Research Institute of Rheumatology (34A Kashirskoye Shosse, Moscow 115522, Russia)

2 Federal Research Center "Informatics and Management of the Russian Academy of Sciences" (44-2 Vavilova Str., Moscow 119333, Russia)

${ }^{3}$ Kazakh National Medical University named after S. D. Asfendiyarova (92 Tole Bi Str., Almaty 50012, Kazakhstan)

Corresponding author: Olga A. Gromova, e-mail: unesco.gromova@gmail.com 


\section{SUMIMARY}

Introduction. The COVID-19 pandemic revealed the vulnerability of the general population to this infectious disease, which is determined by the lack of immunity to the new SARS-CoV-2 coronavirus and is characterized by cytokine storm in severe cases. One of the most important reasons for this vulnerability is a high occurrence rate of micronutrient deficiencies, and above all, vitamin $D$ deficiency.

Aim. To systematize the available data on the role of vitamin D in the prevention of COVID-19 infection.

Materials and methods. Systematic computer analysis of the entire array of available scientific publications on coronaviruses (21,300 publications in PUBMED and preprint repositories, including 7,500 publications on COVID-19 and SARS-CoV-2) was performed. The methods of topological and metric data analysis were used. About 50 most informative sections were identified that were mainly associated with COVID-19 / SARS-CoV-2. The analysis of the obtained "map" of molecular pathophysiology of COVID-19 was performed.

Results. Vitamin D activates the expression of many genes involved in supporting the immunity against coronaviruses and other singlestranded RNA viruses (interferon-dependent protection). The results of the systematic analysis of the publications on coronavirus showed that vitamin $\mathrm{D}$ is important for attenuating the effects of the cytokine storm and compensating for chronic comorbid pathologies.

Conclusion. The compensation for vitamin D deficiency is an essential component of COVID-19 prevention. This tactics of prevention is less costly than managing patients with severe forms of COVID-19 and can help save public healthcare resources.

\section{KEY WORDS}

COVID-19, RNA viruses, micronutrients, cholecalciferol, Aquadetrim, Spraydetrim.

Received: 14.05.2019; in the revised form: 02.06.2020; accepted: 15.06.2020.

\section{Conflict of interests}

The authors declare they have nothing to disclosure regarding the funding or conflict of interests with respect to this manuscript.

The authors contributed equally to this article.

\section{Funding}

The study was funded by the RFBR grants 19-07-00356, 18-07-00944.

\section{For citation}

Gromova O.A., Torshin I. Yu., Gabdulina G. Kh. COVID-19 pandemic: protective role of vitamin D. FARMAKOEKONOMIKA. Sovremennaya farmakoekonomika i farmakoepidemiologiya / FARMAKOEKONOMIKA. Modern Pharmacoeconomics and Pharmacoepidemiology. 2020; 13 (2): 132-145 (in Russ.). https://doi.org/10.17749/2070-4909/farmakoekonomika.2020.044.

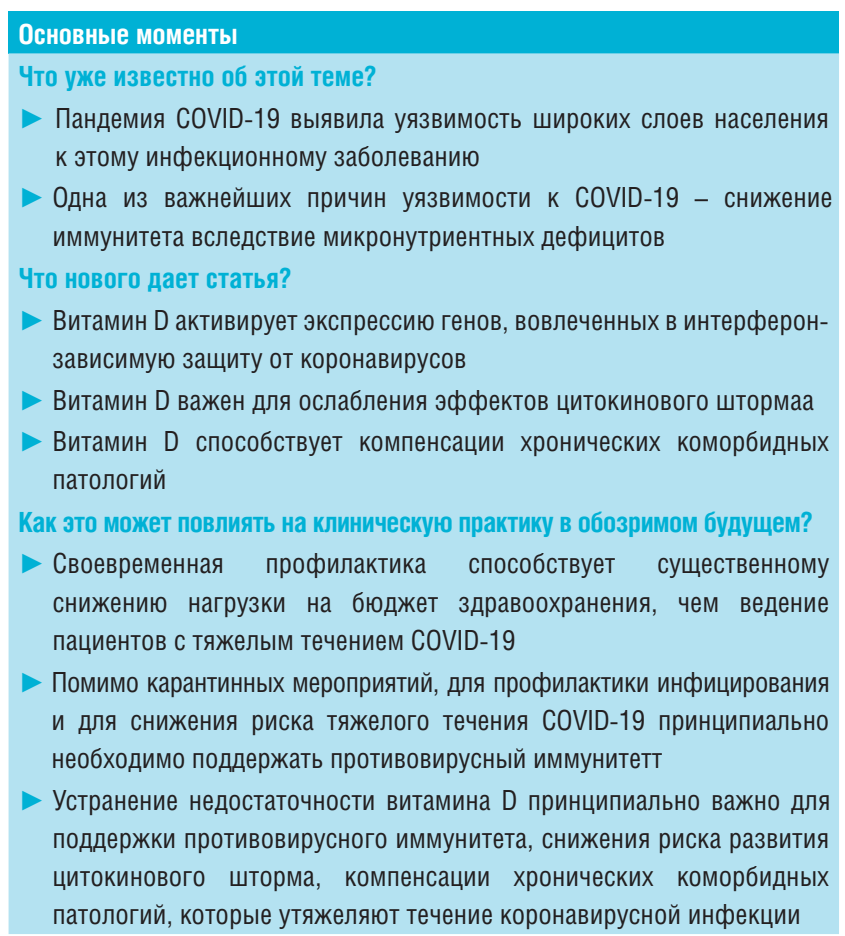

Highlights
COVID is already known about this subject?
infectious disease
One of the most important reasons for vulnerability to COVID-19 is the
decrease in immunity due to micronutrient deficiencies
What are the new findings?
Vitamin D activates the expression of genes involved in interferon-depen-
dent protection against coronaviruses
Vitamin D is important for attenuating the effects of the cytokine storm..
Vitamin D contributes to the compensation for chronic comorbid patholo-
gies
How might it impact on clinical practice in the foreseeable future?
Timely prevention helps significantly reduce the burden on the public
healthcare budget, which is less costly than managing patients with se-
vere COVID-19
In addition to quarantine measures, antiviral immunity support is essen-
tial to prevent infection and to reduce the risk of severe COVID-19
The elimination of vitamin D deficiency is crucial to support antiviral
immunity, reduce the risk of developing a cytokine storm, and compen-
sate for chronic comorbid pathologies that exacerbate the course of
coronavirus infection




\section{BBEДEHИE / INTRODUCTION}

Коронавирусная инфекция COVID-19 была официально зарегистрирована в В03 31 декабря 2019 г., когда министерство здравоохранения КНР сообщило о 44 случаях атипичной пневмонии в городе Ухань провинции Хубэй. Было установлено, что COVID-19 вызывается новым коронавирусом SARS-CoV-2. 11 марта 2020 г. B03 объявила о присвоении COVID-19 статуса пандемии.

Опасность иноеекции COVID-19 заключается в более высокой контагиозности (несколько раз выше, чем грипп), длительным инкубационным перидом (до 14 дней) и осложняется тем, что пациенты без каких-либо симптомов являются переносчиками иноекции. COVID-19 характеризуется тяжелым течением при наличии у пациентов хронической патологии.

Эти особенности COVID-19 предъявляют повышенные требования к организации системы здравоохранения. В частности, более высокая контагиозность приводит к одновременному заболеванию COVID-19 большого числа людей, что привело к перегрузке систем здравоохранения в ряде стран. Более тяжелое течение инфекции при наличии у пациентов хронической патологии ассоциировано с необходимостью применения искусственной вентиляции легких (ИВЛ) и с более высокой смертностью.

Считается, что наиболее важной мерой является понижение скорости распространения инсрекции для снижения пиковой нагрузки на лечебные учереждения. Однако попытки борьбы с коронавирусной инсрекцией COVID-19 только карантинными мерами (ношение масок, перчаток, мытье рук, ограничение социальных контактов, самоизоляция и т.п.) не задействуют важнейший ресурс профилактики - активацию систем врожденного противовирусного иммунитета. Данный аспект особенно важен в случае COVID-19, так как эта инсекция высоко контагиозна и может приводить к тяжелой пневмонии и к острой дыхательной недостаточности.

Для выявления групп риска тяжелого течения заболевания необходимо систематизировать особенности патогенеза COVID-19, отличающие его от других коронавирусных инфекций.

Цель - систематизировать доступные данные о роли витамина D в просилактике инфекции COVID-19.

\section{МАТЕРИАЛЫ И МЕТОДЫ / MATERIALS AND METHODS}

Исследование выполнено в период с 1 по 30 марта 2020 г. В качестве основного источника информации использована база данных медицинских публикаций Pubmed/MEDLINE. Поиск также oxватил репозитории препринтов открытого доступа (например, medRxiv, разделы Ahead of Print научных журналов), поскольку многие научные публикации по новой коронавирусной инфекции доступны только там вследствие короткого времени, прошедшего с начала пандемии. Поиск выполняли по поисковым запросам "coronavirus", "COVID-19", "SARS-CoV-2".

На первом этапе был идентифицирован весь доступный до 30 марта 2020 г. массив публикаций имеющейся научной литературы по коронавирусам (21300 публикаций, в т.ч. 7500 публикаций по COVID-19/SARS-CoV-2). На следующем этапе в результате систематического компьютерного анализа литературы методами топологического [1,2] и метрического анализа данных [3,4] были выделены окло 50 наиболее информативных рубрик, ассоциированных преимущественно с COVID-19/SARS-CoV-2, но не с другими коронавирусами. В результате была получена своего рода «карта» молекулярной патосизиологии COVID-19.

\section{РЕЗУЛЬТАТЫ И ОБСУЖДЕНИЕ / RESULTS AND DISCUSSION}

Анализ полученной «карты» молекулярной патофизиологии COVID-19 (рис. 1) показал, что биомедицинские термины, характерно ассоциированные с COVID-19/SARS-CoV-2, формируют два кластера: кластер 1 «Воспаление и формирование цитокинового шторма» и кластер 2 «Коморбидные состояния». Витамин D занимает важное промежуточное положение между этими двумя кластерами, то есть недостаточность витамина D ассоциирована с патофизиологическими процессами, перечисленными в обоих кластерах.

\section{Тактика терапии COVID-19}

Тактически в терапии COVID-19 очень важно не допустить развитие цитокинового шторма - лавинообразного нарастания концентраций провоспалительных цитокинов, приводящего к по-

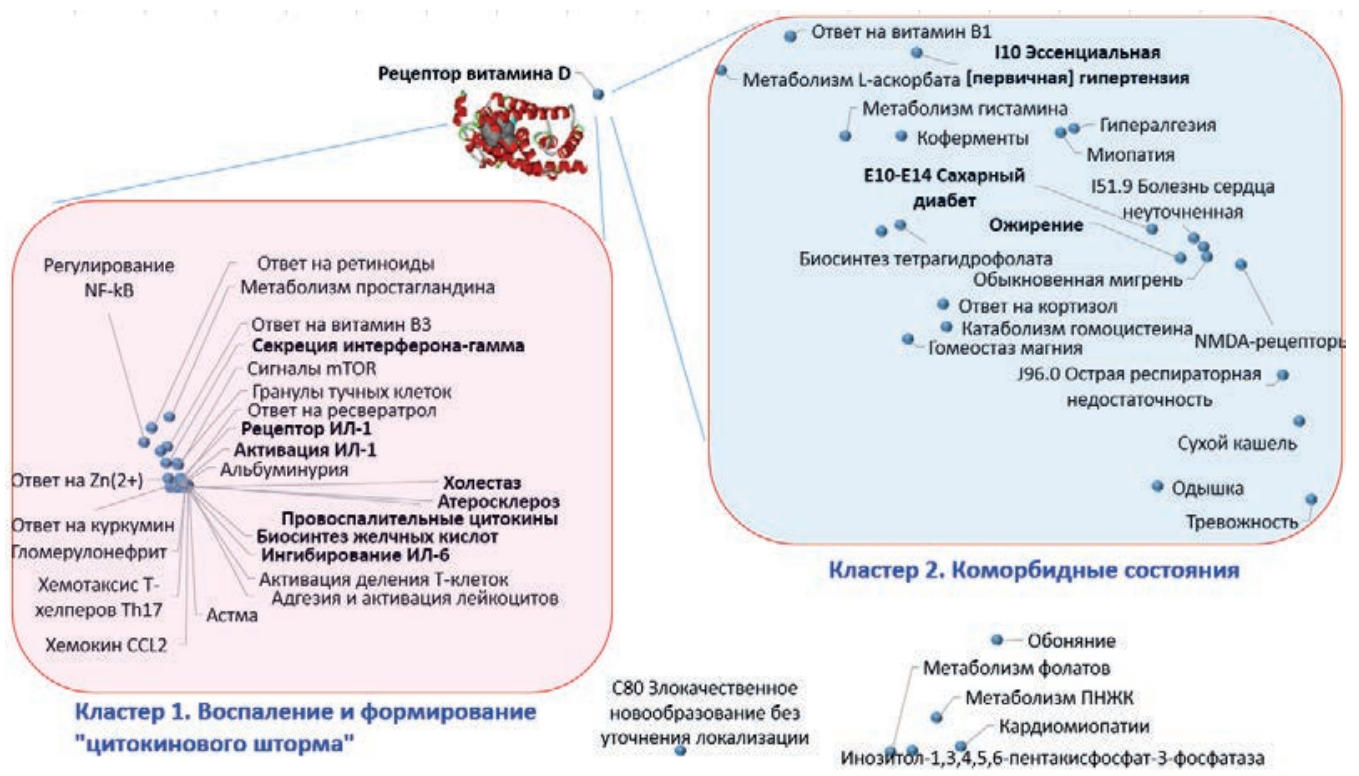

Рисунок 1. Метрическая диаграмма, отражающая «карту» молекулярной патофизиологии COVID-19.

Примечание. Приведены диагнозы по МКБ-10, отдельные симптомы и соответствующие биологические процессы по международной номенклатуре GO (Gепе Ontology). Расстояние между любыми двумя точками, соответствующими двум терминам, тем меньше, чем выше совместная встречаемость терминов в исследованной выборке публикаций по коронавирусам.

Figure 1. Metric diagram that reflects the "map" of molecular pathophysiology of COVID-19.

Note. Diagnosis by the IDC-10, separate symptoms, and the respective biological processes by the intenational GO classification (Gene Ontology) are presented. The shorter the distance between any two points, corresponding to two terms, the higher is the coocurrence of the terms used in the sampling of the publications on coronaviruses. 
вреждениям легких, снижению оксигенации и, как следствие, к необходимости применения оксигенотерапии (кислородотерапии или ИВЛ). Если не допустить развитие этого процесса, то летальность пациентов с COVID-19 резко снизится. Наличие у пациента любого очага хронического воспаления (гломерулонесрита, холестаза, атеросклероза, ожирения, сахарного диабета, бронхиальной астмы, диссрункции эндотелия при артериальной гипертонии и т.п.) стимулирует более быстрое усиление синтеза провоспалительных цитокинов, В т.ч. интерлейкина-1 (G0:0004909, G0:0004908), хемокина CCL2 (G0:0035715), интерлейкина-6 (G0:0070104), интерферона-гамма (G0:1902715). Интерлейкины повышают активацию лейкоцитов (G0:0050902) и распад гранул тучных клеток (G0:0042629). Эти процессы осуществляются при участии витамина D (G0:0008434) и ряда других микронутриентов (цинк, витамин А, витамин PP, см. рисунок 1).

\section{Стратегия терапии COVID-19}

Стратегически важной в терапии и профилактике COVID-19 является компенсация хронических коморбидных патологий, так как наличие у пациента кардиомиопатии, тромбоэмболии, ожирения, артериальной гипертонии, ИБС, сахарного диабета ассоциировано с риском более тяжелого течения COVID-19 (cм. рис. 1). Снижение избыточного хронического воспаления и компенсация коморбидных патологий связаны с повышением обеспеченности витамином D (G0:0008434) и другими микронутриентами (цинк, фолаты, витамин В1, магний, омега-3 ПНЖК, миоинозитол, витамин С). В частности, компенсация недостаточности витамина $D$ имеет важное значение для активации интерферон-зависимого противовирусного иммунитета, для профилактики цитокинового шторма и для компенсации хронических коморбидных патологий.

\section{Распространенность десицита витамина D}

Недостаточность витамина D встречается у 80\% жителей Росии [5]. Кросс-секционное исследование концентрации 25(OH)D в шести регионах Казахстана у 1347 здоровых взрослых 44ะ14 лет (из которых 819 были женщины) показало, что самый низкий уровень витамина D (<10 нг/мл) наблюдался у женщин (34,6\%) по сравнению с мужчинами $(16,7 \%)$ и был значительно выше у азиатов $(33,2 \%)$. Также в исследовании отмечено, что встречаемость тяжелого гиповитаминоза D (<10 нг/мл) выше у лиц с низким индексом массы тела $(31,1 \%)$ по сравнению с лицами с высоким индексом массы тела (18,7\%) [6]. Дефицит витамина D ассоциирован с нарушениями функционирования врожденного и приобретенного иммунитета и с повышением риска вирусных и бактериальных заболеваний. На фоне недостаточности витамина D у пациента любого возраста возникает хроническое воспаление, которое существенно снижает резистентность организма к бактериальным и вирусным заболеваниям (ОРВИ, грипп, ринит, бронхит, обструктивные заболевания легких) [5].

\section{Роль витамина D в регуляции иммунитета}

Витамин D является одним из важнейших регуляторов иммунитета. Адекватная обеспеченность организма витамином D - одна из основ противовирусного иммунитета, В Т. ч. против вируса гриппа [7]. Метаанализы подтвердили, что дотации витамина D облегчают течение ОРВИ, вызванных вирусом гриппа, и других инфекций респираторного тракта у взрослых и детей [8].

Иммунорегулирующий эффект активной формы витамина D (кальцитриол 1,25(ОН)2D3) обусловлен широким спектром воздействия кальцитриола на метаболизм и активность макрофагов, Т- и В-клеток [9]. Кальцитриол способствует снижению уровней провоспалительных цитокинов ИЛ-6, ФНО-альфа, CXCL8, CXCL10, стимулирует синтез антимикробных пептидов(кателицидин, десенсин), которые также проявляют противовирусные свойства $[10,11]$. Наличие рецептора витамина D (VDR) и витамин-D3-метаболизирующих фрерментов (CYP27B1 и др.) в моноцитах, макрофрагах, В- и Т-клетках указывает на то, что клетки иммунной системы могут синтезировать и использовать активную форму витамина 1,25(OH)2D3 для поддержания клеточного иммунитета (рис. 2).

В случае с инфекцией COVID-19 витамин D важен тем, что активирует описанные выше системы врожденного противовирусного

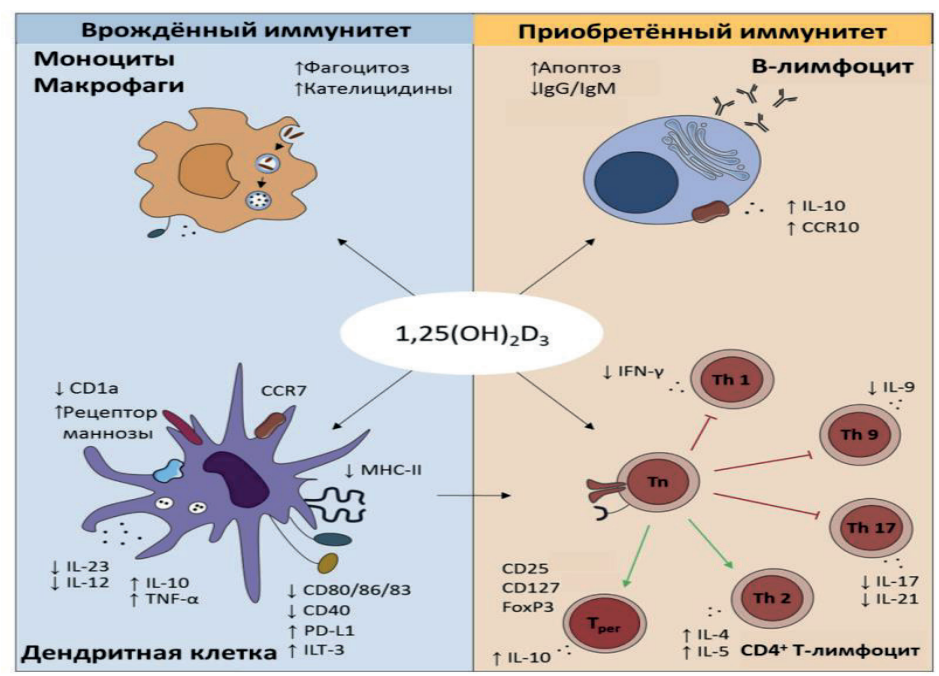

Рисунок 2. Иммуномодулирующие эффекты витамина D.

Примечание. Активная форма витамина 1,25(ОН)2D3 оказывает влияние на клетки врожденного и приобретенного иммунитета. В моноцитах и в макрофагах 1,25(ОН)2D3 усиливает антимикробную активность, увеличивая фагоцитарный ответ наряду с усилением синтеза антибактериальных и противовирусных пептидов (кателицидин, дефенсин). В дендритных клетках 1,25(ОН)2D3 подавляет экспрессию антиген-представляющих молекул МНС-II и СD1а, молекулкорецепторов CD40 и CD80/86/83), провоспалительных цитокинов ИЛ-12 и ИЛ-23. 1,25(ОН)2D3 также непосредственно влияет на ответ Т-клеток путем ингибирования продуцирования цитокинов Тh1 (интерферон-гамма), Тh9 (ИЛ-9) и Тh17(ИЛ-17, ИЛ-21), стимулируя Тh2-цитокины (ИЛ-4, ИЛ-5).

Figure 2. Immune modulating effects of vitamin D.

Note. Active form of vitamin 1.25(OH)2D3 influences the cells of congenital and acquired immunity. In monocytes and macrophages, $1.25(\mathrm{OH}) 2 \mathrm{D} 3$ enhances antibacterial activity by increasing the phagocytic response and the synthesis of antibacterial and antiviral peptides (cathelicidin, defensing). In dendrite cells, $1.25(\mathrm{OH}) 2 \mathrm{D} 3$ suppresses the expression of antigen-presenting molecules MCH-II and CD 1a, molecule-coreceptors CD40 and CD80/86/83, anti-inflammatory cytokines IL-12 and IL-23. 1.25(OH) 2D3 also directly influences the response of T-cells by inhibiting the production of cytokines Th1 (interferon-gamma), Th9 (IL-9), and Th17 (IL-17, IL-21) and stimulating Th2-cytokines (IL-4, IL-5). 
иммунитета. Коронавирус SARS-CoV-2 (геном NC_045512.2 в базе данных NCBI) - вирус с одноцепочечной РНК, вирион которого содержит специальные спайк-белки (от англ. - spike - шип, острие, острый выступ), посредством которых вирус активно взаимодействует с тканями организма человека. РНК-вирусы характеризуются высокой степенью мутаций по сравнению с ДНК-содержащими вирусами, так как вирусные РНК-полимеразы характеризуются низкой степенью исправления ошибок копирования PHK [10]. Быстрая разработка эффрективной и безопасной вакцины к SARS-CoV-2 маловероятна [12]. Поэтому для борьбы с COVID-19 важно использовать все возможные способы повышения противовирусного иммунитета и, прежде всего, повышение обеспеченности организма витамином D среди широких слоев населения.

\section{Дефицит витамина D и COVID-19}

Анализ инсормации об уровнях 25(OH)D среди населения 20 европейских стран, а также о заболеваемости и смертности от COVID-19 указал на отрицательные корреляции между средними уровнями 25(OH)D и количеством случаев COVID-19 на 1 млн населения (в среднем, 296) и смертностью на 1 млн (в среднем, 5,96) (рис. 3). Уровни 25(ОН)D были наиболее снижены у пожилых пациентов из Италии, Испании и Швейцарии [14].

Полногеномный анализ VDR и протеомный анализ микронутриент-зависимых белков

Эфсректы витамина D на организм осуществляются при участии рецептора VDR (англ. - vitamin D receptor). Рецептор VDR специфически активируется кальцитриолом и приводит к изменениям экспрессии более 2700 генов человека. Полногеномный систем- но-биологический анализ связывания рецептора витамина D позволил осуществить систематизацию биологических ролей витамина D для просилактики и терапии широкого круга заболеваний [15]. В частности, было установлено, что в поддержке противовирусного иммунитета участвуют, по меньшей мере, 155 белков, экспрессия генов которых регулируется рецептором витамина $D$ (рис. 4).

Полученные в работе [15] результаты полногеномного анализа VDR показали, что 19 из 155 генов/белков имеют непосредственное отношение к защите от одноцепочечных РНК-вирусов, к которым относится и SARS-CoV-2. Витамин D стимулирует экспрессию генов, кодирующих интерсерон-индуцированные белки с тетратрикопептидными повторами (гены IFIT1, IFIT3, IFIT5), интерсрерон-регуляторные фракторы (IRF1, IRF3, IRF7, IRF9), убиквитиноподобный модификатор ISG15, 20 кДа экзонуклеазу, стимулируемую интерфероном (ISG20), белки устойчивости к миксовирусам, в Т.ч. к гриппу (MX1, MX2), 2'-5'-олигоаденилатсинтетазы (OAS1, OAS2), рецептор ретиноидов RXRA, белки-регуляторы противовирусного ответа TRIM22, TRIM38, TRIM56, убиквитин, играющий важные роли в поддержании противовирусного иммунитета к РНК-вирусам (UBB, UBC), цинковый палец ZNF175, торм0зящий репликацию вирусов.

Сопоставление приведенных выше результатов полногеномного анализа рецептора VDR с результатами протеомного анализа микронутриент-зависимых белков противовирусной защиты человека указывает на синергидные взаимодействия витамина D c другими микронутриентами. В протеоме человека содержится более 35000 белков, из которых 19820 были аннотированы (то есть для которых известны выполняемые ими биологические роли). Методом анализа фуннкциональных взаимосвязей [16] мы выделили 820 белков, вовлеченных в защиту организма против вирусов, из которых 178
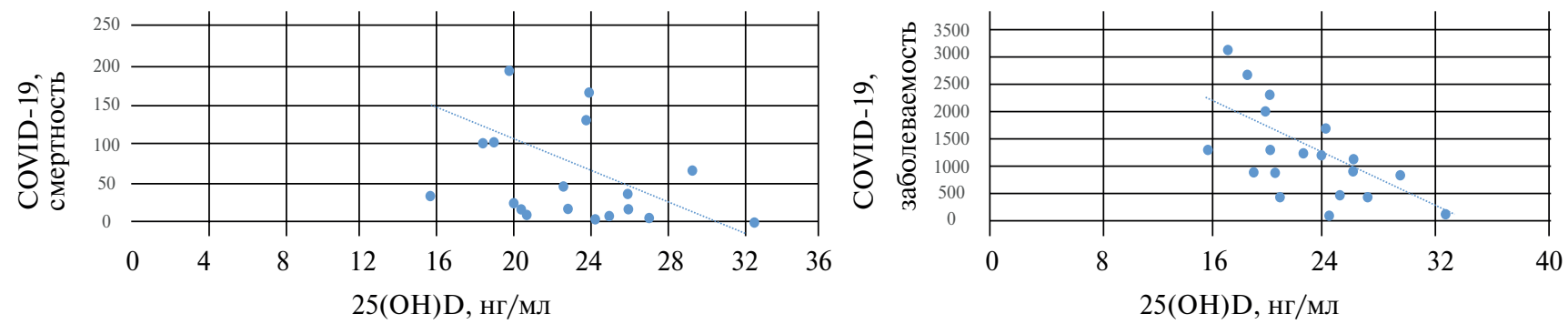

Рисунок 3. Средние уровни витамина D и заболеваемость/смертность от COVID-19 (на 1 млн населения). Точки соответствуют разным странам (по данным [14]).

Figure 3. Mean levels of vitamin D and the morbidity/lethality rate from COVID-19 (per $1 \mathrm{mln}$ of the population). The points correspond with different countries [14]

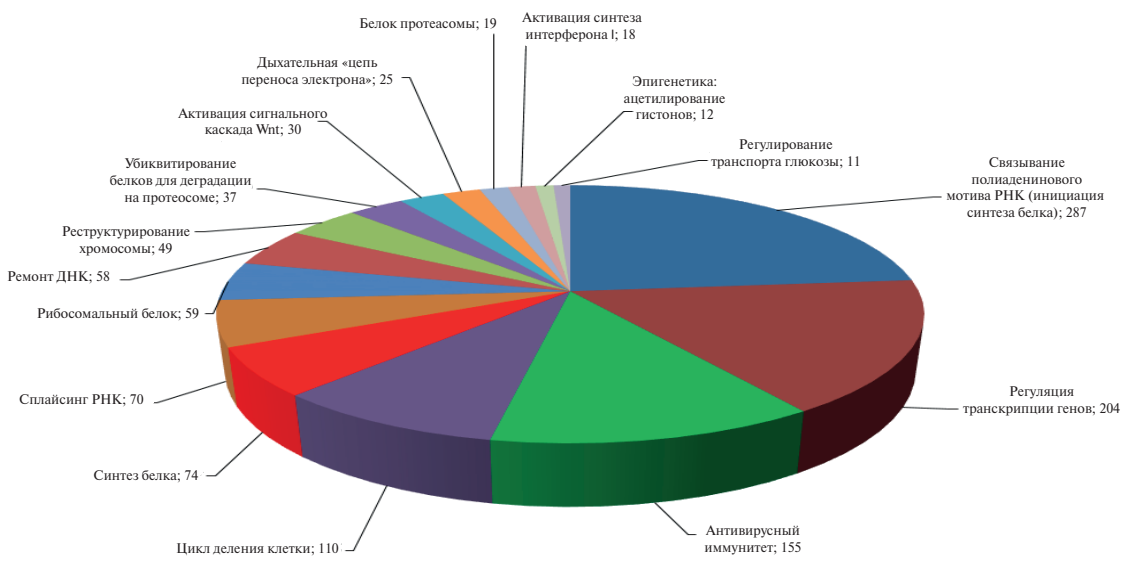

Рисунок 4. Полногеномный анализ эффектов витамина D указал на существование 155 белков противовирусной защиты, экспрессия генов которых регулируется витамином $\mathrm{D}[15]$.

Figure 4. Genome-wide analysis of the effects of vitamin D revealed 155 proteins of antivarial protection that are regulated by vitamin D [15]. 
имели те или иные нутриентные кофакторы (цинк, магний, производные витаминов и др.). Из этого числа 22 белка имеют непосредственное отношение к защите организма от одноцепочечных РНК вирусов. Экспрессия генов, кодирующих многие из этих белков, зависит от активности рецептора витамина D (табл. 1).

\section{Роль VDR-зависимых белков в противовирусной защите орга- низма}

Результаты системно-биологического анализа показали, что практически все белки, перечисленные в таблице 1, участвуют в интерферон-зависимой противовирусной защите организма человека. Эти белки и соответствующие микронутриенты (цинк, магний, марганец, кальций, железо, селен, фолаты, витамины А и РP) важны для ингибирования различных стадий жизненного цикла одноцепочечных РНК-вирусов. При десицитах этих нутриентов активность соответствующих белков будет неизбежно снижаться, тем самым ухудшая эффективность интерфероновой системы противовирусной защиты. Поэтому целесообразно применять препараты витамина D в сочетании с перечисленными выше микронутриентами. Сопоставление результатов полногеномного анализа рецептора витамина D с результатами протеомного анализа показывает, что многие из белков, участвующих в торможении жизненного цикла одноцепочечных РНК-вирусов, зависят от витамина D и того или иного микронутриента (рис. 5).

Таким образом, рецептор витамина D регулирует экспрессию многих генов защиты организма против одноцепочечных РНК вирусов. Эта противовирусная система организма будет эфффективна и для защиты от коронавирусов.

\section{Метаанализы связи дотаций витамина D и течения ОРВИ}

Хотя в случае SARS-CoV-2 пока не имеется данных крупных эпидемиологических исследований, для одноцепочечных PHК вируcoв, вызывающих ОРВИ (RSV, вирус гриппа и др.), было показано, что витамин D ассоциирован с состоянием противовирусной защиты организма. В частности, метаанализ 25 рандомизированных исследований $(\mathrm{n}=10933)$, проведенный с использованием данных об индивидуальных пациентах, показал, что дотации витамина D способствовали снижению риска инсрицирования ОРВИ в среднем на 12\% (0.Р. 0,88; 95\% ДИ: 0,81-0,96; Р<0,001). Среди пациентов, имевших более одного эпизода ОРВИ в год, риск повторного заболевания ОРВИ снижался на 20\% при приеме витамина D (ОР 0,80; 95\% ДИ: 0,69-0,93; Р=0,004) (рис. 6) [17].

Метаанализ 11 плацебо-контролируемых исследований, включающий в себя 5660 пациентов, еще раз подтвердил защитный эффект приема препаратов витамина D против вирусных инфекций дыхательных путей (ОР 0,64; 95\% ДИ: 0,49-0,84). Защитный эффект был достоверно выше при ежедневном приеме витамина D в средней дозе 1600 ME/сут. (2-4 мес.) по сравнению с «ударной» болюсной дозировкой (100000 МЕ, однократно за 3 мес.). Так, при ежедневном приеме витамина D риск инфекций снижался на 49\% (ОР 0,51), а при использовании «болюсной» дозировки всего на 14\% (OP 0,86; $p=0,01)$ [18].

Цитокиновый шторм и витамин-D-зависимые механизмы иммунного ответа на коронавирусы

Острая фраза воспаления при респираторно-вирусных инфекциях сопровождается отеком слизистой носа и бронхов разной степени выраженности. У пациентов с неблагоприятным аллергическим фоном происходит усиленный выброс гистамина, брадикинина и других медиаторов аллергического воспаления. Течение инфекции COVID-19 осложнено тем, что описанные выше процессы протекают гораздо в более острой фрорме, нежели при обычном ОРВИ или при гриппе, преимущественно с вовлечением нижних дыхательных путей.

\section{Патогенез цитокинового шторма}

Для вируса SARS-CoV-2 характерно стимулирование развития так называемого “цитокинового шторма», лавинообразного нарастания выработки многих маркеров воспаления (СРБ, ИЛ6, IFN-ү и др.), которое сопровождается усилением апоптоза лимфоцитов и существенно утяжеляет течение инфекции [19]. Такие «цитокиновые штормы», по всей видимости, являются причиной повреждений легких по типу «матовое стекло» [20] и особенно опасны для пожилых пациентов или молодых пациентов с коморбидными состояниями (ожирение, СД2, тромбосиилии, ДВС-синдром и др.) $[19,20]$.

Цитокиновый шторм инициируется при взаимодействии спайк-белков и других белковых частиц на капсиде коронавируса с рецепторами на поверхности клеток. Анализ траскриптома клеток 119 типов из 13 различных тканей человека показал, что молекулами-рецепторами для SARS-CoV-2 являются ангиотензин-превращающий фрермент 2 (ACE2), пептидазы ANPEP, ENPEP, DPP4R и толл-рецепторы [21]. Взаимодействие вирусов с толл-подобными рецепторами (TLR3 и др.) (рис. 7) приводит к активации воспалительного сигнального каскада NF-kB. Активация NF-kB стимулирует секрецию проинтерлейкина-1, который подвергается протеолизу при участии каспазы- 1 , что приводит к активации ин-

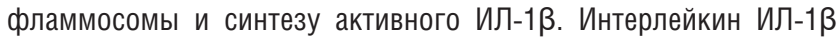
является медиатором воспаления и фиброза легких, лихорадки, стимулируя секрецию других провоспалительных цитокинов. Ингибирование эффектов ИЛ-1 $\beta$ и ИЛ-6 оказывает терапевтическое воздействие при многих патологиях, связанных с воспалением, В Т.ч. при вирусных инфекциях. Эфффекты ИЛ-1ß ослабляются посредством ингибирования сигнального белка mTOR и повышения активности аденозинмоносоосфат киназы (AMPK) [22].

\section{Роль витамина D в контроле цитокинового шторма}

Снижение риска формирования цитокинового шторма при COVID-19 следует осуществлять противовоспалительными средствами (в частности, направленными против избыточной активации NF-kB). Витамин D, модулируя активность Т-лимфоцитов, тучных клеток, антиген-презентирующих клеток, способствует ослаблению чрезмерного воспалительного ответа, повышая уровни противовоспалительного ИЛ-10, снижая уровни $\lg \mathrm{E}$, цитокинов-аларминов, ИЛ-17, гистамина, лейкотриенов [23]

Для цитокинового шторма, развивающегося в легких, исключительно важно исходное состояние легочной ткани. Например, если у пациента имеется бронхиальная астма, то эпителий бронхов подвержен постоянной инфильтрации эозиносилами, макрофагами и В-клетами, секретирующими иммуноглобулин Е. Эти изменения в легочной ткани не только облегчают проникновение вируса, но и создают условия для быстрого формирования цитокинового шторма. Клинические исследования показали, что сниженные уровни 25(ОН)D в крови способствуют повышению риска развития бронхиальной астмы (особенно в инфекционно-аллергической форме), обструктивного бронхита, аллергического ринита. В частности, аллергический компонент астмы характеризуется развитием патологической иммунной гиперреакции на аэроаллергены (в т.ч. переносящие вирусные частицы). Метаанализ 21 исследования $(\mathrm{n}=11993)$ показал, что дефицит витамина $\mathrm{D}$ связан с повышенным риском тяжелой ХОБЛ. Десрицит витамина D был связан с повышенным риском ХОБЛ (ОР 1,77; 95\% ДИ: 1,18-2,64; $\mathrm{P}=0,006)$ и с более тяжелым течением ХОБЛ (ОР 2,83; $95 \%$ ДИ: $2,00-4,00 ; P<0,001)[24]$

Недостаточность витамина D $(25(\mathrm{OH}) \mathrm{D}<20$ нг/мл) ассоциирована с более тяжелым состоянием госпитализированных с инфекцией нижних дыхательных путей и респираторно-синцитиальным вирусом. Дефицит витамина установлен у 50\% обследованных и был ассоциирован с 3-кратным риском поступления пациента в реанимацию (ОР 3,29; 95\% ДИ: 1,20-9,02; P=0,018) и с 11-крат- 
Таблица 1. Белки защиты организма от одноцепочечных РНК вирусов, активность которых зависит от микронутриентных кофакторов (результаты системно-биологического анализа протеома человека).

Table 1. The activity of protective proteins from one-chain RNA viruses that depends on micronutrient cofactors (results of systemic-biological analysis of human proteome)

\begin{tabular}{|c|c|c|c|}
\hline Ген & Белок & Кофактор & Функция белка \\
\hline $\begin{array}{l}\text { TRIM25/ } \\
\text { ISG15* }\end{array}$ & $\begin{array}{l}\text { Е3 убиквитин лигаза ISG15 / } \\
\text { E3 ubiquitin ligase ISG15 }\end{array}$ & $\begin{array}{l}\mathrm{Zn}(2+), \text { вит. A / } \\
\mathrm{Zn}(2+) \text {, vit. A }\end{array}$ & $\begin{array}{l}\text { Запускает продукцию интерферонов. Экспрессия зависит } \\
\text { от ретиноидов (витамин A) / Initiates the production } \\
\text { of interferons. The expression depends on retinoids (Vitamin A) }\end{array}$ \\
\hline SIRT1 & $\begin{array}{l}\text { НАД деацетилаза сиртуин-1/ } \\
\text { NAD DAC sirtuin-1 }\end{array}$ & $\begin{array}{l}\mathrm{Zn}(2+), \text { НАД / } \\
\mathrm{Zn}(2+), \text { NAD }\end{array}$ & $\begin{array}{c}\text { Деацетилирует и ингибирует NF-кB (НАД - витамин PP) / } \\
\text { Deacetylates and NF-kB (NAD - vitamin PP) }\end{array}$ \\
\hline ZC3H12A & $\begin{array}{c}\text { Эндорибонуклеаза MCPIP-1 } \\
\text { (регназа-1) / Endoribonuclease } \\
\text { MCPIP-1 (regnase-1) }\end{array}$ & $\mathrm{Zn}(2+), \mathrm{Mg}(2+)$ & $\begin{array}{c}\text { Дестабилизирует вирусную РНК, } \\
\text { снижает избыточное воспаление / } \\
\text { Destabilizes viral RNA, reduces excessive inflammation }\end{array}$ \\
\hline SAMHD1 & $\begin{array}{l}\text { ДНК фоссфогидролаза / DNA } \\
\text { phosphohydrolase }\end{array}$ & $\mathrm{Zn}(2+)$ & $\begin{array}{c}\text { Расщепляет одноцепочечную вирусную PHK, } \\
\text { ограничивает активацию NF-кB / } \\
\text { Splits one-chain viral RNA and reduces the activation of NF-KB }\end{array}$ \\
\hline SIVA1 & $\begin{array}{l}\text { CD27-связывающий белок / } \\
\text { CD27-binding protein }\end{array}$ & $\mathrm{Zn}(2+)$ & Ингибирует активацию NF-кB / Inhibits the activation of NF-кB \\
\hline TRIM5 $\alpha^{*}$ & $\begin{array}{l}\text { Е3 убиквитин лигаза / E3 ubiquitin } \\
\text { ligase }\end{array}$ & $\operatorname{Zn}(2+)$ & $\begin{array}{l}\text { Тормозит высвобожение вирусной PHK / } \\
\text { Suppresses the expression of viral RNA }\end{array}$ \\
\hline ZC3HAV1 & $\begin{array}{l}\text { Антивирусный белок-1 ZAP / } \\
\text { Antiviral protein-1 ZAP }\end{array}$ & $\mathrm{Zn}(2+)$ & $\begin{array}{l}\text { Способствует удалению белковой защиты вирусной PHK / } \\
\text { Promotes the removal of protein protection of viral DNA }\end{array}$ \\
\hline $\begin{array}{l}\text { RNF216 } \\
\text { TRIM22* }\end{array}$ & $\begin{array}{l}\text { Е3 убиквитин-лигазы / } \\
\text { E3 ubiquitin ligase }\end{array}$ & $\mathrm{Zn}(2+)$ & $\begin{array}{c}\text { Ингибируют репликацию вируса и вызванную вирусом } \\
\text { активацию NF-кB / Inhibits the replication of the virus and the } \\
\text { activation of NF-кB caused by the virus }\end{array}$ \\
\hline TRIM26* & $\begin{array}{l}\text { Белок «кислотный цинковый } \\
\text { палец» AFP / "Acid zinc finger" } \\
\text { protein AFP }\end{array}$ & $\begin{array}{l}\mathrm{Zn}(2+) \\
\mathrm{Se}\end{array}$ & $\begin{array}{l}\text { Регулирует продукцию IFN-бета / } \\
\text { Regulates the production of IFN-beta }\end{array}$ \\
\hline TNFAIP3 & $\begin{array}{l}\text { ФНО-индуцированный белок } 3 \text { / } \\
\text { TNF-induced protein } 3\end{array}$ & $\mathrm{Zn}(2+)$ & Прекращает активацию NF-кB / Inhibits the activation of NF-кB \\
\hline ZFP36 & $\begin{array}{l}\text { Белок-активатор распада мPHK } \\
\text { ZFP36 / Activator-protein of the } \\
\text { degradation of mRNA ZFP36 }\end{array}$ & $\mathrm{Zn}(2+)$ & $\begin{array}{c}\text { Подавляет синтез ФНО-альфа в интерфрерон-индуцированных } \\
\text { макрофрагах / Suppresses the synthesis of TNFa in interferon- } \\
\text { induced macrophages }\end{array}$ \\
\hline RNASEL & Рибонуклеаза L / Ribonuclease L & $\operatorname{Mn}(2+), \operatorname{Mg}(2+)$ & $\begin{array}{c}\text { Расщепляет одноцепочечные вирусные PHK, ингибирует синтез } \\
\text { вирусных белков / Splits one-chain viral RNA, inhibits the } \\
\text { synthesis of viral proteins }\end{array}$ \\
\hline PPM1B & $\begin{array}{l}\text { Протеинфоссфатаза 1B / } \\
\text { Protein phosphatase 1B }\end{array}$ & $\mathrm{Mn}(2+), \mathrm{Mg}(2+)$ & $\begin{array}{c}\text { Прекращает ФНО-альфра-опосредованную активацию NF-кB / } \\
\text { Stops TNFa mediated activation of NF-кB }\end{array}$ \\
\hline ISG20* & $\begin{array}{c}20 \text { кДа интерферон- } \\
\text { стимулированный белок / } \\
20 \text { kDa interferon-stimulating protein }\end{array}$ & $\operatorname{Mn}(2+)$ & Деградирует вирусную PHK / Degrades viral RNA \\
\hline $\begin{array}{c}O A S 1^{*} \\
O A S 2^{*}, O A S 3\end{array}$ & $\begin{array}{l}\text { Олигоаденилатсинтазы / } \\
\text { Oligoadenylate synthases }\end{array}$ & $\mathrm{Mg}(2+)$ & $\begin{array}{l}\text { Активируют рибонуклеазу L, приводит к деградации вирусной } \\
\text { PHK / Activate ribonuclease L, leads to the degradation of viral RNA }\end{array}$ \\
\hline RIOK3 & $\begin{array}{l}\text { Серин/треонин-протеинкиназа RI03 // } \\
\text { Serin/threonine-protein kinase RI03 }\end{array}$ & $\mathrm{Mg}(2+)$ & $\begin{array}{c}\text { Синтез интерсреронов-I при врожденном иммунном ответе } \\
\text { против PHK вирусов / Synthesis of interferons-I in the congenital } \\
\text { immunity response to RNA viruses }\end{array}$ \\
\hline PLSCR1 & $\begin{array}{l}\text { Фоссролипидная скрамблаза } 1 / \\
\text { Phospholipid scramblase } 1\end{array}$ & $\mathrm{Ca}(2+)$ & $\begin{array}{l}\text { Усиливает эффекты интерферона-альфа посредством } \\
\text { повышения экспрессии генов / Enhances the effects } \\
\text { of interferon-alfa by increasing the expression of the gene }\end{array}$ \\
\hline RSAD2 & $\begin{array}{l}\text { Виперин / } \\
\text { Viperin }\end{array}$ & $\begin{array}{l}\text { [4Fe-4S], (фолаты) / } \\
{[4 \mathrm{Fe}-4 \mathrm{~S}], \text { (folates) }}\end{array}$ & $\begin{array}{l}\text { Подавляет отщепление вируса от плазматической мембраны, } \\
\text { способствует продукции IFN- } \beta \text {, активации Т-клеток / Suppresses } \\
\text { the separation of the virus from the plasmic membrane, contributes } \\
\text { to the production of IFN- } \beta \text {, activation of T-cells }\end{array}$ \\
\hline $\mathrm{CH} 25 \mathrm{H}$ & $\begin{array}{l}\text { Холестерин-25-гидроксилаза / } \\
\text { Cholesterol-25-hydroxylase }\end{array}$ & $\begin{array}{l}\mathrm{Fe}, \mathrm{HАДФ} \mathrm{/} \\
\mathrm{Fe}, \mathrm{NADPH}\end{array}$ & $\begin{array}{l}\text { Тормозит вход вирусов в клетку и сборку белковой оболочки } \\
\text { вируса. НАДФ - витамин PP / Inhibits the penetration of the virus into } \\
\text { the cell and the assembly of protein viral coating. NADPH - vitamin PP }\end{array}$ \\
\hline
\end{tabular}

* Гены, экспрессия которых может в существенной степени регулироваться рецептором витамина D.

* The expresson of the genes that can be regulated by the receptor of vitamin $D$. 


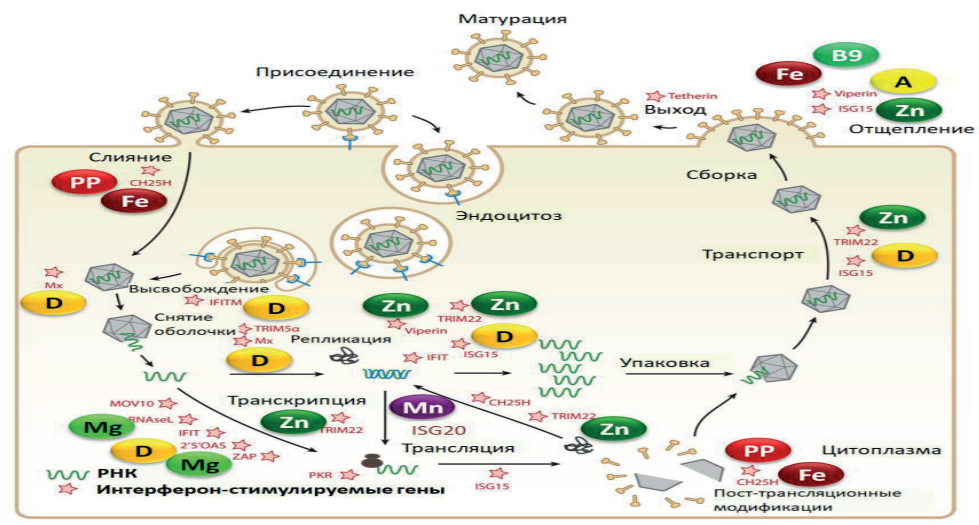

Рисунок 5. Витамин D и его синергисты в контексте интерферон-зависимой противовирусной защиты.

Примечание. Звездочками отмечены гены, экспрессия которых стимулируется интерферонами 1-го типа (рисунок адаптирован из работы [11]).

Figure 5. Vitamin D and its synergists in the context of interferon-dependent antiviral protection.

Note. Stars marks are depicted next to the gene, which expression is stimulated by interferons of I type (the Figure is adapted from [11]).

ным риском назначения пациенту ИВЛ (ОР 11,20; 95\% ДИ: 2,27$55,25 ; \mathrm{P}<0,001)[25]$.

В клиническом исследовании (n=669) было показано, что недостаточность витамина D ассоциирована с повышением количества эозиносилов в крови. Достоверные различия были установлены между подгруппой участников с тяжелым дефицитом витамина D $(25(\mathrm{OH}) \mathrm{D}<10$ нг/мл) при сравнении со всеми остальными подгруппами пациентов (10-20 нг/мл, 20-30 нг/мл, $\geq 30$ нг/мл) [26].

Заметим, что исходное состояние ткани легких также зависит от курения. Результаты систематического анализа 10 клиникоэпидемиологических исследований ( $\mathrm{n}=76993)$ показали, что ку- рение (обследованных) является столь же важным фактором риска инсицирования SARS-CoV-2, как гипертония $(10,2$ $23,7 \%)$, ИБС $(4,4-22,8 \%)$ и диабет $(6,6-9,3 \%)$ [27]. Метаанализ 11 клинических исследований $(\mathrm{n}=2002)$ показал, что риск тяжелого течения COVID-19 возрастает в 2 раза у курильщиков и в 4,4 раза - у пациентов с ХОБЛ (как правило, курильщики с большим стажем) [28].

Метаанализ девяти когортных исследований европейцев

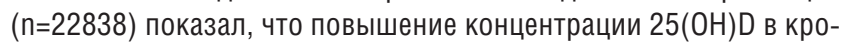
ви на каждый 1 нМ объем форсированного выдоха в секунду (FEV1) увеличивался на 1,1 мл (95\% ДИ: 0,9-1,3; P<0,0001). Дан-

\section{Исследование}

Li-Ng 2009
Urashima 2010
Manaseki-Holland 2010
Laaksi 2010
Majak 2011
Trilok-Kumar 2011
Lehouck 2012
Manaseki-Holland 2012
Camargo 2012
Murdoch 2012
Bergman 2012
Marchisio 2013
Rees 2013
Tran 2014
Goodall 2014
Urashima 2014
Grant 2014
Martineau 2015 (ViDiCO)
Martineau 2015 (ViDiAs)
Martineau 2015 (ViDiFlu)
Dubnov-Raz 2015
Denlinger 2016
Tachimoto 2016
Ginde 2016
Simpson 2015

\section{Контроль}

$33 / 76(43.4)$

$69 / 167$ (41.3)

$126 / 229(55.0)$

$54 / 84(64.3)$

$11 / 24(45.8)$

$458 / 1030(44.5)$

$29 / 89(32.6)$

245/1505 (16.3)

$53 / 103(51.5)$

$155 / 161(96.3)$

$39 / 62(62.9)$

$38 / 58(65.5)$

276/360 (76.7)

$96 / 197(48.7)$

$80 / 234(34.2)$

$17 / 99(17.2)$

$53 / 80(66.3)$

$75 / 118(63.6)$

93/125 (74.4)

$58 / 103(56.3)$

$10 / 11(90.9)$

$93 / 207(44.9)$

$5 / 35$ (14.3)

24/52 (46.2)

$14 / 16(87.5)$

\section{Витамин D}

$$
\begin{gathered}
32 / 81(39.5) \\
68 / 167(40.7) \\
97 / 224(43.3) \\
39 / 80(48.8) \\
4 / 24(16.7) \\
438 / 1034(42.4) \\
30 / 86(34.9) \\
260 / 1506(17.3) \\
44 / 141(31.2) \\
154 / 161(95.7) \\
26 / 62(41.9) \\
26 / 58(44.8) \\
303 / 399(75.9) \\
185 / 397(46.6) \\
70 / 258(27.1) \\
32 / 148(21.6) \\
94 / 156(60.3) \\
76 / 122(62.3) \\
85 / 125(68.0) \\
83 / 137(60.6) \\
10 / 14(71.4) \\
110 / 201(54.7) \\
4 / 54(7.4) \\
17 / 55(30.9) \\
16 / 18(88.9)
\end{gathered}
$$

Скорректированное О.Ш.

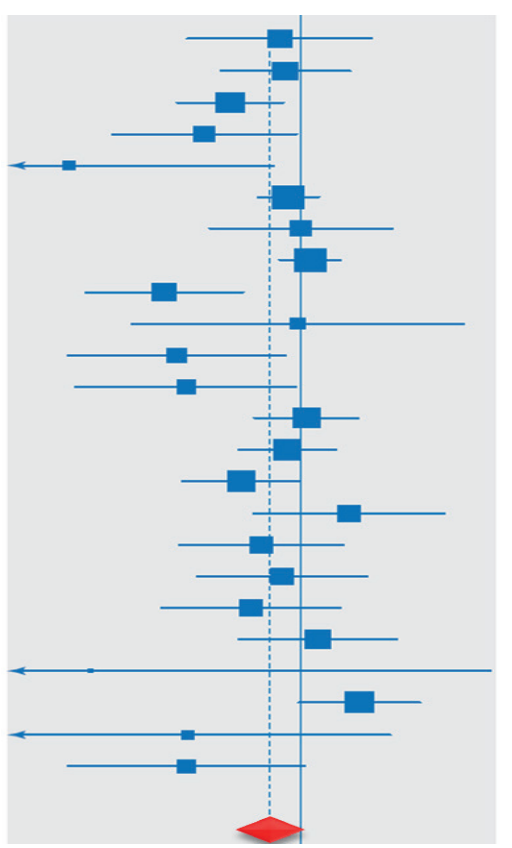

Вес, \% О.Ш., 95\% ДИ

$3.48 \quad 0.85(044$ to 1.64$)$

$5.36 \quad 0.90(0.58$ to 1.41$)$

$6.12 \quad 0.60$ (0.41 to 0.88$)$

$3.58 \quad 0.51$ ( 0.27 to 0.96$)$

$0.20(0.05$ to 0.82$)$

$0.92(0.77$ to 1.11$)$

$1.00(0.53$ to 1.90$)$

1.08 ( 0.89 to 1.30$)$

$0.38(0.22$ to 0.65

$0.97(0.30$ to 3.15$)$

$0.42(0.20$ to 0.89$)$

$0.44(0.21$ to 0.95$)$

$1.03(0.72$ to 1.49$)$

$0.92(0.65$ to 1.30$)$

$0.66(0.45$ to 0.98$)$

1.43 ( 0.73 to 2.78$)$

0.77 ( 0.43 to 1.36$)$

0.87 ( 0.48 to 1.57$)$

$0.71(0.38$ to 1.31$)$

1.13 ( 0.66 to 1.95$)$

0.23 (0.01 to 3.82$)$

1.52 ( 1.02 to 2.28$)$

0.45 (0.11 to 1.89$)$

$0.44(0.19$ to 1.02$)$ Искл

$0.80(0.69$ to 0.93$)$

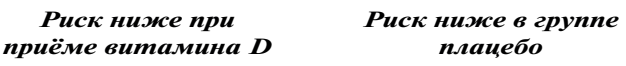

Рисунок 6. Метаанализ 25 рандомизированных исследований показал защитный эффект дотаций витамина D против ОРВИ: доля пациентов, имевших одну и более ОРВИ, при применении витамина D меньше, чем в контрольной группе (адаптировано из источника [17]). Примечание. О.ШІ. - отношение шансов; ДИ-доверительный интервал.

Figure 6. A meta-analysis of 25 randomized studies showed a protective effect vitamin D against ARVI: the share of patients that had one or more ARVIs was lower in the group that received vitamin D than in the control group (adapted from [17]).

Note. OR - odds ratio; CI- confidential interval. 


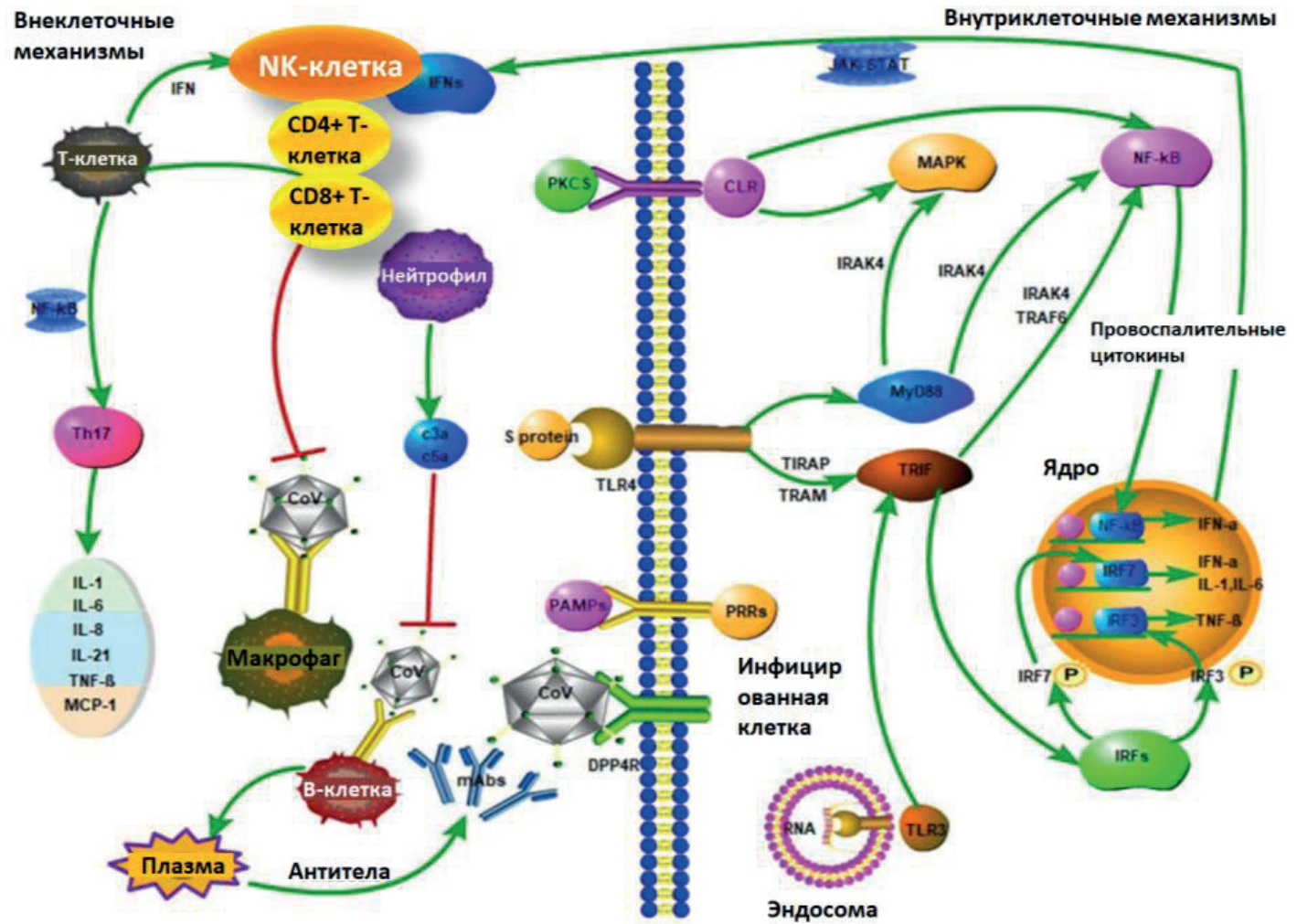

Рисунок 7. Молекулярные механизмы иммунного ответа на коронавирусы (адаптировано из [22].

(Слева) Коронавирус (CoV) заражает макрофаги, которые представляют СоV-антигены T-клеткам. Происходит активация и дифференцировка Т-клеток, что стимулирует последующее высвобождением цитокинов. Однако избыточный синтез цитокинов (т.н. «иитокиновый шторм») оказывает негативное влияние на активаиию NK и CD8 T-клеток. (Справа) Присоединение CoVк рецептору DPP4R через белок $S$ приводит к появлению геномной вирусной РНК в иитоплазме. Pецептор TLR-3, сенсибилизированный вирусной РНК и каскадами сигнальных путей (IRF и активация NF-хB соответственно) активируется для продукции интерферонов типа I и провоспалительных цитокинов. TLR-4 может распознавать белок $S$ и приводить к активации провоспалительных цитокинов через MyD88-зависимый сигнальный путь. Интенсивная секреция хемокинов и цитокинов $I L-1, I L-6, I L-8, I L-21, T N F-\beta$ и MCP-1 стимулируется в инфииированных клетках в ответ на инфекиию CoV, что вызывает хемокинез лимфоцитов и лейкоиитов в место инфекции.

Figure 7. Molecular mechanisms of the immune response to coronaviruses (adapted from [22]).

(Left) Coronavirus (CoV) infects macrophages that provide $\mathrm{CoV}$-antigenes to T-cells. The activation and differentiation of T-cells are observed, which stimulates further cytokine release. However, the excessive synthesis of cytokines (i.e. cytokine storm) negatively influences the activation of NK and CD8 T-cells. (Right) The attachment of CoV to the receptor DPP4R via S protein leads to the appearance of genome viral RNA in the cytoplasm. The receptor TLR-3, sensibilized by the viral RNA and cascades of signalin pathways (IRF and activation of $N F-x B$, respectively), gets activated for the production of interferons type I and anti-inflammatory cytokines. TLR-4 can identify $S$ protein and lead to the activation of anti-inflammatory cytokines via the MyD88-dependent signaling pathway. Intensive secretion of chemokines and cytokines $I L-1, I L-6, I L-8, I L-21$, TNF- $\beta$, and MCP-1 is stimulated in the infected cells in response to CoV infection, which provides chemokinesis of lymphocytes and leukocytes to the site of infection.

ная ассоциация была еще более выражена у курильщиков: объем FEV1 увеличивался на 1,7 мл (95\% ДИ: 1,1-2,3) на каждый 1 нM 25(OH)D. Таким образом, компенсация недостаточности витамина $D$ является особо важным резервом реабилитации для курильщиков [29].

\section{Хронические патологии и десицит витамина D}

Широчайший круг биологических функций генов/белков, регулируемых витамином D (см. рис. 4), обуславливает профилактические и лечебные роли не только при вирусных инфекциях, но и при заболеваниях, отягощающих течение COVID-19. Сложнейший комплекс взаимосвязей между низкой обеспеченностью витамином D и многочисленными коморбидными заболеваниями детально описан в нашей книге «Витамин D - смена парадигмы» [5]. Препараты витамина D важны для просрилактики и лечения многих хронических заболеваний: метаболического синдрома и сахарного диабета, артериальной гипертонии и заболеваний почек, тромбофилии, ишемической болезни сердца, хронической ишемии мозга, неспецифического язвенного колита, опухолевых заболеваний, нарушений иммунитета (в т.ч. системного хронического воспаления), нарушений репродуктивного здоровья и др.

Течение COVID-19, зачастую, связано не только с очевидными нарушениями дыхательной системы, но и с диссуннкцией других систем органов. Инфекция COVID-19 ассоциирована с повышением уровней маркеров дисфункции печени (АСТ, АЛТ, альбумина билирубина [30], срерритина), которые также ассоциированы с более тяжелым течением пневмонии и с наличием симтоматики со стороны ЖКТ (тошнота, рвота, диарея) [31].

Пациенты с COVID-19 характеризуются выраженными нарушениями коагуляционного профиля крови [19]. Прокоагулянтные нарушения профиля свертываемости крови (повышение уровней D-димера, продуктов деградации фрибрина) ассоциированы с более высоким риском смертности от COVID-19 [32]. Более высокие уровни плазмина соответствуют усилению фибринолиза и повышению уровней D-димера при тяжелом течении COVID-19 [33]. Хорошо известно, что витамин D способствует нормализации просриля коагуляции крови [5].

Важно понимать, что наличие у пациента хронических коморбидных патологий является патофизиологическим объяснением более тяжелого течения COVID-19, особенно у пожилых пациентов. Например, в многоцентровом китайском исследовании $(\mathrm{n}=280)$ доля пациентов старше 65 лет достоверно выше среди тяжелых случаев (59\%), чем в случае пациентов с легким течением инсрекции $(10,2 \% ; P<0,05)$. При этом 85,5\% пациентов с тяжелым течением COVID-19 также имели сахарный диабет или стенокардию, которые встречались в 7-10 раз чаще $(P=0,042)$, чем у пациентов с легкой формой COVID-19 [34]. 
Метаанализ восьми клинических исследований пациентов

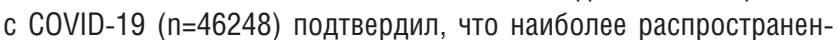
ными коморбидными состояниями были АГ (17\%), СД2 (8\%), ИБС $(5 \%)$, заболевания легких и/или бронхов. Коморбидные состояния соответствовали увеличению риска тяжелого течения инфекции COVID-19: АГ - в 2,4 раза (95\% ДИ: 1,5-3,8), респираторные - в 2,5 раза (95\% ДИ: 1,8-3,4), ИБС - в 3,4 раза (95\% ДИ: 1,88-6,22) [35].

Факторы риска смертности от COVID-19 включают наличие артериальной гипертонии (АГ), сахарного диабета 2-го типа (СД2), ишемической болезни сердца (ИБС), цереброваскулярных патологий [36]. Среди пациентов с COVID-19 на фоне СД2 чаще отмечаются критические состояния, требующие вмешательства реаниматологов [37]. Все перечисленные патологии (СД2, АГ, ИБС, ХОБЛ, бронхиальная астма) ассоциированы с недостаточностью витамина D [5].

O водорастворимых формах витамина D и профилактике/терапии COVID-19

Фармакологические и физико-химические исследования показали, что кишечная абсорбция витамина D наиболее полно происходит из растворов так называемых «мицелл» — коллоидных наночастиц 10-1000 нм в диаметре, образующих мелкодисперсную взвесь в большом объеме растворителя. Мицеллы - наночастицы c «жировой начинкой» (содержащей витамин D) и гидросильной оболочкой, которая и позволяет наночастицам равномерно распределяться по всему объему водного раствора (рис. 8) [5].

В водной среде мицеллы образуются особыми амфифильными молекулами (поверхностно активными веществами, ПАВ или эмульгаторами), то есть молекулами, имеющими гидрофобный «хвост» (выталкиваемый из водного раствора вследствие сил поверхностного натяжения) и гидрофильную «головку» (наоборот, обладающую повышенным сродством к водному раствору). Такими молекулами являются, например, триглицериды. Соли желчных кислот, образуемые в печени и секретируемые из желчного пузыря, также стимулируют мицеллообразование жирных кислот.

Мицеллообразование имеет важное значение для усвоения организмом жирорастворимых витаминов D, A, E и K. Поэтому мицеллированные («водорастворимые») растворы витамина D (Аквадетрим) обеспечивают хорошую степень всасывания у па- циентов с патологией печени и нарушениями желчеобразования, страдающих алкоголизмом, атеросклерозом и нарушениями сункции печени при COVID-19 [5]. При состояниях, связанных с патологией ЖKT, восполнение десицита витамина D также возможно достичь за счет использования биологический активных добавок к пище представленных в виде орального спрея витамина $D$ (Спрейдетрим). Попадание капель микроразмера раствора витамина D в полость рта обеспечивает достаточно быстрое и практически полное всасывание за счет поверхностно расположенных многочисленных капилляров и вен в слизистой оболочке щеки и в полости рта [38].

\section{ЗАКЛЮЧЕНИЕ / CONCLUSION}

COVID-19 характеризуется высокой контагиозностью, значительной долей пациентов с тяжелым течением заболевания и с необходимостью применения затратных медицинских технологий (ИВЛ, интенсивная терапия, и т.п.), с длительной реабилитацией. Для COVID-19 характерны осложнения (фиброз легких, повреждения миокарда, нервной системы, печени и почек), которые могут привести к инвалидности. Фармакоэкономические исследования и оценка различных медицинских технологий, применяемых на госпитальном этапе ведения пациентов с новой коронавирусной инфекцией, еще только предстоит выполнить. Однако уже сейчас ясно, что своевременная профилактика способствует существенному снижению нагрузки на бюджет здравоохранения, чем ведение пациентов с тяжелым течением COVID-19. Поэтому, помимо карантинных мероприятий, для профилактики инсрицирования и для снижения риска тяжелого течения COVID-19 принципиально необходимо поддержать противовирусный иммунитет, снизить риск развития цитокинового шторма и компенсировать коморбидные патологии, которые утяжеляют течение коронавирусной инфекции. Устранение недостаточности витамина D принципиально важно для достижения всех этих задач. Витамин D3 (холекальцисрерол) при респираторно-вирусной инсрекции (грипп, COVID-19, RSV-инфекция) следует применять в просиилактических дозах (1000-2000 MЕ/сут.) на постоянной основе. Пациентам с хроническими коморбидными патологиями, утяжеляющими течение COVID-19, рекомендуется прием 4000-5000 ME/сут. в течение 3-6 месяцев.

Рисунок 8. Мицеллярные структуры, образуемые поверхностно активными веществами в водном растворе.

Figure 8. Micellar structures formed by superface-active substances in water solutions. 


\section{ЛИТЕРАТУРА:}

1. Torshin I. Yu., Rudakov K.V. On metric spaces arising during formalization of recognition and classification problems. part 1 : properties of compactness. Pattern Recognition and Image Analysis (Advances in Mathematical Theory and Applications). 2016; 26 (2): 274.

2. Torshin I. Yu., Rudakov K. V. On metric spaces arising during formalization of problems of recognition and classification. part 2: density properties. Pattern Recognition and Image Analysis (Advances in Mathematical Theory and Applications). 2016; 26 (3): 483-496.

3. Torshin I. Yu. Optimal Dictionaries output information based on the criterion of Solvability and their applications in Bioinformatics. Pattern recognition and image analysis. 2013; 23 (2): 319-327.

4. Torshin I. Yu., Rudakov K. V. Combinatorial analysis of the solvability properties of the problems of recognition and completeness of algorithmic models. part 2: metric approach within the framework of the theory of classification of feature values. Pattern Recognition and Image Analysis (Advances in Mathematical Theory and Applications). 2017; 27 (2): 184-199.

5. Громова О.А., Торшин И. Ю. Витамин D. Смена парадигмы. Под ред. Е. И. Гусева, И. Н. Захаровой. М. 2017; 568 с.

6. Gromova O., Doschanova A., Lokshin V., Tuletova A., Grebennikova G., Daniyarova L., Kaishibayeva G., Nurpeissov T., Khan V., Semenova Y., Chibisova A., Suzdalskaya N., Aitaly Z., Glushkova N. Vitamin D deficiency in Kazakhstan: Cross-Sectional study. J Steroid Biochem Mol Biol. 2020 May; 199: 105565. DOl: https://doi.org/10.1016/j. jsbmb.2019.105565.

7. Colotta F., Jansson B., Bonelli F. Modulation of inflammatory and immune responses by vitamin D. J Autoimmun. 2017 Dec; 85: 7897. D0I: https://doi.org/10.1016/j.jaut.2017.07.007.

8. Beard J. A., Bearden A., Striker R. Vitamin D and the anti-viral state. J Clin Virol. 2011 Mar; 50 (3): 194-200. doi: 10.1016/j.jcv.2010.12.006.

9. Charan J., Goyal J.P., Saxena D., Yadav P. Vitamin D for prevention of respiratory tract infections: A systematic review and meta-analysis. J Pharmacol Pharmacother. 2012 0ct; 3 (4): 300-3. doi: https://doi.org/10.4103/0976-500X.103685.

10. Vanherwegen A.S., Gysemans C., Mathieu C. Regulation of Immune Function by Vitamin D and Its Use in Diseases of Immunity. Endocrinol Metab Clin North Am. 2017 Dec; 46 (4): 1061-1094. DOl: https://doi.org/10.1016/j.ecl.2017.07.010. Epub 2017 Oct 6.

11. Schneider W. M., Chevillotte M.D., Rice C. M. Interferon-stimulated genes: a complex web of host defenses. Annu Rev Immunol. 2014; 32: 513-545.DOl:https://doi.org/10.1146/annurev-immunol-032713-120231.

12. Prajapat M., Sarma P., Shekhar N., Avti P., Sinha S., Kaur H., Kumar S., Bhattacharyya A., Kumar H., Bansal S., Medhi B. Drug targets for corona virus: A systematic review. Indian J Pharmacol. 2020 JanFeb; 52 (1): 56-65. DOI: https://doi.org/10.4103/ijp.IJP_115_20.

13. Daneshkhah A., Agrawal V., Eshein A., Subramanian H., Roy H. K., Backman V. The possible role of vitamin $d$ in suppressing cytokine storm and associated mortality in COVID-19 patients. DOI: https://doi. org/10.1101/2020.04.08.20058578.

14. Ilie P.C., Stefanescu S., Smith L. The role of vitamin D in the prevention ofcoronavirus disease 2019 infection and mortality. Aging Clin Exp Res. 2020 May 6. DOl: https://doi.org/10.1007/s40520-020-01570-8.

15. Громова О.А., Торшин И. Ю., Спиричев В.Б. Полногеномный анализ сайтов связывания рецептора витамина D указывает на широкий спектр потенциальных применений витамина D в терапии. Медицинский совет. 2016; 1: 12-21.

16. Torshin I. Yu (Ed. Gromova OA). Sensing the change from molecular genetics to personalized medicine. Nova Biomedical Books, NY, USA, 2009. In "Bioinformatics in the Post-Genomic Era" series.

17. Martineau A. R., Jolliffe D. A., Hooper R. L., Greenberg L., Aloia J.F., Bergman P., Dubnov-Raz G., Esposito S., Ganmaa D., Ginde A. A., Goodall E. C., Grant C.C., Griffiths C.J., Janssens W., Laaksi I., Manaseki-Holland S., Mauger D., Murdoch D.R., Neale R., Rees J.R., Simpson S. Jr., Stelmach I., Kumar G. T., Urashima M.,
Camargo C.A. Jr. Vitamin D supplementation to prevent acute respiratory tract infections: systematic review and meta-analysis of individual participant data. BMJ. 2017 Feb 15; 356: i6583. DOI: https://doi.org/10.1136/bmj.i6583.

18. Bergman P., Lindh A. U., Björkhem-Bergman L., Lindh J. D. Vitamin $D$ and Respiratory Tract Infections: A Systematic Review and MetaAnalysis of Randomized ControlledTrials. PLoS One. 2013 Jun 19; 8 (6): e65835. DOI: https://doi.org/10.1371/journal.pone.0065835.

19. Макацария А.Д., Григорьева К.Н., Мингалимов М.А., Бицадзе В.О., Хизроева Д.Х., Третьякова М. В., Элалами И., Шкода А. С., Немировский В.Б., Блинов Д.В., Митрюк Д.В. Коронавирусная инсекция (COVID-19) и синдром диссеминированного внутрисосудистого свертывания. Акушерство, Гинекология и Репродукция. 2020; 14 (2) 123-131; DOI: https://doi. org/10.17749/2313-7347.132.

20. Salehi S., Abedi A., Balakrishnan S., Gholamrezanezhad A. Coronavirus Disease 2019 (COVID-19): A Systematic Review of Imaging Findings in 919 Patients. AJR Am J Roentgenol. 2020 Mar 14: 1-7. DOI: https://doi.org/10.2214/AJR.20.23034.

21. Qi F., Qian S., Zhang S., Zhang Z. Single cell RNA sequencing of 13 human tissues identify cell types and receptors of human coronaviruses. Biochem Biophys Res Commun. 2020 Mar 18. pii: S0006291X(20)30523-4. D0I: https://doi.org/10.1016/j.bbrc.2020.03.044.

22. Li G., Fan Y., Lai Y., et al. Coronavirus infections and immune responses. J Med Virol. 2020; 92 (4): 424-432. DOI: https://doi. org/10.1002/jmv.25685.

23. Pfeffer P.E., Hawrylowicz C.M. Vitamin D in Asthma: Mechanisms of Action and Considerations for Clinical Trials. Chest. 2018 May; 153 (5): 1229-1239. DOl: https://doi.org/10.1016/j. chest.2017.09.005. Epub 2017 Sep 18.

24. Zhu M., Wang T., Wang C., Ji Y. The association between vitamin $\mathrm{D}$ and COPD risk, severity, and exacerbation: an updated systematic review and meta-analysis. Int $J$ Chron Obstruct Pulmon Dis. 2016 Oct 19; 11: 2597-2607. DOl: https://doi.org/10.2147/COPD. S101382. eCollection 2016. PMID: 27799758.

25. Hurwitz J. L., Jones B. G., Penkert R. R., Gansebom S., Sun Y., Tang L. et al. Low Retinol-Binding Protein and Vitamin D Levels Are Associated with Severe Outcomes in Children Hospitalized with Lower Respiratory Tract Infection and Respiratory Syncytial Virus or Human Metapneumovirus Detection. J Pediatr. 2017; 187: 323-327. DOI: https://doi.org/10.1016/j.jpeds.2017.04.061.27.

26. Souto Filho J. T.D., de Andrade A. S., Ribeiro F. M., Alves P. A.S., Simonini V.R.F. Impact of vitamin D deficiency on increased blood eosinophil counts. Hematol Oncol Stem Cell Ther. 2018 Mar; 11 (1): 25-29. DOI: https://doi.org/10.1016/j.hemonc.2017.06.003. Epub 2017 Aug 16. PMID: 28830802.

27. Emami A., Javanmardi F., Pirbonyeh N., Akbari A. Prevalence of Underlying Diseases in Hospitalized Patients with COVID-19: a Systematic Review and Meta-Analysis. Arch Acad Emerg Med. 2020 Mar 24; 8 (1): e35. eCollection 2020. PMID: 32232218.

28. Zhao Q., Meng M., Kumar R., Wu Y., Huang J., Lian N., Deng Y., Lin S. The impact of COPD and smoking history on the severity of Covid-19: A systemic review and meta-analysis. J Med Virol. 2020 Apr 15. DOI: https://doi.org/10.1002/jmv.25889. PMID: 32293753.

29. Xu J., Bartz T.M., Chittoor G., Eiriksdottir G., Manichaikul A.W., Sun F., Terzikhan N., Zhou X., Booth S.L., Brusselle G.G., de Boer I.H., Fornage M., Frazier-Wood A.C., Graff M., Gudnason V., Harris T.B., Hofman A., Hou R., Houston D.K., Jacobs D. R., Kritchevsky S.B., Latourelle J., Lemaitre R.N., Lutsey P.L., O'Connor G., Oelsner E.C., Pankow J.S., Psaty B.M., Rohde R. R., Rich S.S., Rotter J.I., Smith L.J., Stricker B.H., Voruganti V. S., Wang T. J., Zillikens M.C., Barr R.G., Dupuis J., Gharib S.A., Lahousse L., London S.J., North K.E., Smith A.V., Steffen L.M., Hancock D. B., Cassano P.A. Meta-analysis across Cohorts forHeart and Aging Research in Genomic Epidemiology (CHARGE) consortium providesevidence for an association of serum vitamin 
D with pulmonary function. Br JNutr. 2018 Nov; 120 (10): 1159-1170. DOI: https://doi.org/10.1017/S0007114518002180. PMID: 30205856.

30. Liu C., Jiang Z.C., Shao C.X., Zhang H.G., Yue H.M., Chen Z.H., Ma B.Y., Liu W. Y., Huang H. H., Yang J., Wang Y., Liu H.Y., Xu D., Wang J.T., Yang J.Y., Pan H.Q., Zou S.Q., LiF.J., Lei J.Q., Li X., He Q., GuY., QiX.L. Preliminary study of the relationship between novel coronavirus pneumonia and liver function damage: a multicenter study. Zhonghua Gan Zang Bing Za Zhi. 2020 Feb 20; 28 (2): 148-152. DOl: https://doi.org/10.3760/ cma.j.issn.1007-3418.2020.02.003. PMID: 32077660.

31. Jin X., Lian J. S., Hu J.H., Gao J., Zheng L., Zhang Y.M., Hao S. R., Jia H.Y., Cai H., Zhang X.L., Yu G. D., Xu K.J., Wang X.Y., Gu J.Q., Zhang S.Y., Ye C.Y., Jin C.L., Lu Y.F., YuX., YuX.P., Huang J.R., Xu K.L., Ni Q., Yu C.B., Zhu B., Li Y.T., Liu J., Zhao H., Zhang X., Yu L., Guo Y.Z., Su J.W., Tao J.J., Lang G.J., Wu X.X., Wu W. R., Qv T. T., Xiang D. R., Yi P., Shi D., Chen Y., Ren Y., Qiu Y.Q., Li L.J., Sheng J., Yang Y. Epidemiological, clinical and virological characteristics of 74 cases of coronavirus-infected disease 2019 (COVID-19) with gastrointestinal symptoms. Gut. 2020 Mar 24; pii: gutjnl-2020-320926. DOI: https://doi.org/10.1136/gutjnl-2020-320926. PMID: 32213556.

32. Tang N., Li D., Wang X., Sun Z. Abnormal coagulation parameters are associated with poor prognosis in patients with novel coronavirus pneumonia. J Thromb Haemost. 2020 Apr; 18 (4): 844-847. D0I: https:// doi.org/10.1111/jth.14768. Epub 2020 Mar 13. PMID: 32073213.

33. Ji H.L., Zhao R., Matalon S., Matthay M. A. Elevated Plasmin(ogen) as a Common Risk Factor for COVID-19 Susceptibility. Physiol

\section{REFERENCES:}

1. Torshin I. Yu., Rudakov K. V. On metric spaces arising during formalization of recognition and classification problems. part 1 : properties of compactness. Pattern Recognition and Image Analysis (Advances in Mathematical Theory and Applications). 2016; 26 (2): 274.

2. Torshin I. Yu., Rudakov K.V. On metric spaces arising during formalization of problems of recognition and classification. part 2: density properties. Pattern Recognition and Image Analysis (Advances in Mathematical Theory and Applications). 2016; 26 (3): 483-496.

3. Torshin I. Yu. Optimal Dictionaries output information based on the criterion of Solvability and their applications in Bioinformatics. Pattern recognition and image analysis. 2013; 23 (2): 319-327.

4. Torshin I. Yu., Rudakov K.V. Combinatorial analysis of the solvability properties of the problems of recognition and completeness of algorithmic models. part 2: metric approach within the framework of the theory of classification of feature values. Pattern Recognition and Image Analysis (Advances in Mathematical Theory and Applications). 2017; 27 (2): 184-199.

5. Gromova O. A., Torshin I. Yu. Paradigm shift. Ed. by E. I. Gusev, I. N. Zakharova. Moscow. 2017; 568 s.

6. Gromova 0., Doschanova A., Lokshin V., Tuletova A., Grebennikova G., Daniyarova L., Kaishibayeva G., Nurpeissov T., Khan V., Semenova Y., Chibisova A., Suzdalskaya N., Aitaly Z., Glushkova N. Vitamin D deficiency in Kazakhstan: Cross-Sectional study. J Steroid Biochem Mol Biol. 2020 May; 199: 105565. DOI: https://doi.org/10.1016/j.jsbmb.2019.105565.

7. Colotta F., Jansson B., Bonelli F. Modulation of inflammatory and immune responses by vitamin D. J Autoimmun. 2017 Dec; 85: 7897. DOI: https://doi.org/10.1016/j.jaut.2017.07.007.

8. Beard J.A., Bearden A., Striker R. Vitamin D and the anti-viral state. J Clin Virol. 2011 Mar; 50 (3): 194-200. DOl: 10.1016/j. jcv.2010.12.006.

9. Charan J., Goyal J.P., Saxena D., Yadav P. Vitamin D for prevention of respiratory tract infections: A systematic review and meta-analysis. J Pharmacol Pharmacother. 2012 0ct; 3 (4): 300-3. DOI: https://doi.org/10.4103/0976-500X.103685.
Rev. 2020 Jul 1; 100 (3): 1065-1075. D0I: https://doi.org/10.1152/ physrev.00013.2020. Epub 2020 Mar 27. PMID: 32216698.

34. Wu J., Li W., Shi X., Chen Z., Jiang B., Liu J., Wang D., Liu C., Meng Y., Cui L., Yu J., Cao H., Li L. Early antiviral treatment contributes to alleviate the severity and improve the prognosis of patients with novel coronavirus disease (COVID-19). J Intern Med. 2020 Mar 27; DOI: https://doi.org/10.1111/joim.13063. PMID: 32220033

35. Yang J., Zheng Y., Gou X., Pu K., Chen Z., Guo Q., Ji R., Wang H., Wang Y., Zhou Y. Prevalence of comorbidities and its effects in coronavirus disease 2019 patients: A systematic review and metaanalysis. Int J Infect Dis. 2020 Mar 12; 94: 91-95. DOl: https://doi. org/10.1016/j.ijid.2020.03.017. PMID: 32173574.

36. Madjid M., Safavi-Naeini P., Solomon S. D., Vardeny O. Potential Effects of Coronaviruses on the Cardiovascular System: A Review. JAMA Cardiol. 2020 Mar 27. pii: 2763846. D0I: https://doi.org/10.1001/ jamacardio.2020.1286. PMID: 32219363.

37. Ma W.X., Ran X.W. The Management of Blood Glucose Should be Emphasized in the Treatment of COVID-19. Sichuan Da Xue Xue Bao Yi Xue Ban.2020Mar;51(2):146-150.DOl:https://doi.org/10.12182/20200360606. PMID: 32220179.

38. Satia M. C., Mukim A. G., Tibrewala K. D., Bhavsar M. S. A randomized two way cross over study for comparison of absorption of vitamin D3 buccal spray and soft gelatin capsule formulation in healthy subjects and in patients with intestinal malabsorption. Nutr $\mathrm{J}$. 2015 Oct 29; 14: 114. DOI: https://doi.org/10.1186/s12937-015-01051. PubMed PMID: 26514332; PubMed Central PMCID: PMC4627615.

10. Vanherwegen A. S., Gysemans C., Mathieu C. Regulation of Immune Function by Vitamin $D$ and Its Use in Diseases of Immunity. Endocrinol Metab Clin North Am. 2017 Dec; 46 (4): 1061-1094. DOl: https://doi.org/10.1016/j.ecl.2017.07.010. Epub 2017 0ct 6.

11. Schneider W. M., Chevillotte M. D., Rice C. M. Interferon-stimulated genes: a complex web of host defenses. Annu Rev Immunol. 2014; 32: 513-545.DOl:https://doi.org/10.1146/annurev-immunol-032713-120231.

12. Prajapat M., Sarma P., Shekhar N., Avti P., Sinha S., Kaur H., Kumar S., Bhattacharyya A., Kumar H., Bansal S., Medhi B. Drug targets for corona virus: A systematic review. Indian J Pharmacol. 2020 Jan-Feb; 52 (1): 56-65. DOl: https://doi.org/10.4103/ijp. IJP_115_20.

13. Daneshkhah A., Agrawal V., Eshein A., Subramanian H., Roy H.K., Backman V. The possible role of vitamin d in suppressing cytokine storm and associated mortality in COVID-19 patients. BMJ. DOl: https://doi.org/10.1101/2020.04.08.20058578.

14. Ilie P. C., Stefanescu S., Smith L. The role of vitamin D in the prevention ofcoronavirus disease 2019 infection and mortality. Aging Clin Exp Res. 2020 May 6. DOI: https://doi.org/10.1007/s40520-02001570-8.

15. Gromova 0.A., Torshin I. Yu., Spirichev V.B. A full genome analysis of vitamin $D$ receptor binding sites indicates a wide range of potential uses for vitamin D in therapy. Meditsinskii sovet. 2016; 1 : 12-21 (in Russ).

16. Torshin I. Yu (Ed. Gromova OA). Sensing the change from molecular genetics to personalized medicine. Nova Biomedical Books, NY, USA, 2009. In "Bioinformatics in the Post-Genomic Era" series.

17. Martineau A.R., Jolliffe D.A., Hooper R.L., Greenberg L., Aloia J.F., Bergman P., Dubnov-Raz G., Esposito S., Ganmaa D., Ginde A.A., Goodall E.C., Grant C.C., Griffiths C.J., Janssens W., Laaksi I., Manaseki-Holland S., Mauger D., Murdoch D. R., Neale R., Rees J.R., Simpson S. Jr., Stelmach I., Kumar G.T., Urashima M., Camargo C.A. Jr. Vitamin D supplementation to prevent acute respiratory tract infections: systematic review and meta-analysis of individual participant data. BMJ. 2017 Feb 15; 356: i6583. DOI: https:// doi.org/10.1136/bmj. 6583 . 
18. Bergman P., Lindh A.U., Björkhem-Bergman L., Lindh J.D. Vitamin D and Respiratory Tract Infections: A Systematic Review and Meta-Analysis of Randomized ControlledTrials. PLoS One. 2013 Jun 19; 8 (6): e65835. DOI: https://doi.org/10.1371/journal.pone.0065835.

19. Makatsariya A.D., Grigor'eva K.N., Mingalimov M.A., Bitsadze V. O., Khizroeva D. Kh., Tret'yakova M.V., Elalami I., Shkoda A. S., Nemirovskii V. B., Blinov D. V., Mitryuk D. V. Coronavirus disease (COVID-19) and disseminated intravascular coagulation syndrome. Akusherstvo, ginekologiya i reproduktsiya / Obstetrics, gynecology and reproduction. 2020; 14 (2): 123-131. (in Russ). D0I: https://doi.org/10.17749/2313-7347.132.

20. Salehi S., Abedi A., Balakrishnan S., Gholamrezanezhad A. Coronavirus Disease 2019 (COVID-19): A Systematic Review of Imaging Findings in 919 Patients. AJR Am J Roentgenol. 2020 Mar 14: 1-7. DOI: https://doi.org/10.2214/AJR.20.23034.

21. Qi F., Qian S., Zhang S., Zhang Z. Single cell RNA sequencing of 13 human tissues identify cell types and receptors of human coronaviruses. Biochem Biophys Res Commun.2020Mar 18. pii:S0006-291X(20)30523-4. DOI: https://doi.org/10.1016/j.bbrc.2020.03.044.

22. Li G., Fan Y., Lai Y., et al. Coronavirus infections and immune responses. J Med Virol. 2020; 92 (4): 424-432. DOI: https://doi. org/10.1002/jmv.25685.

23. Pfeffer P.E., Hawrylowicz C.M. Vitamin D in Asthma: Mechanisms of Action and Considerations for Clinical Trials. Chest. 2018 May; 153 (5): 1229-1239. DOI: https://doi.org/10.1016/j. chest.2017.09.005. Epub 2017 Sep 18.

24. Zhu M., Wang T., Wang C., Ji Y. The association between vitamin $\mathrm{D}$ and COPD risk, severity, and exacerbation: an updated systematic review and meta-analysis. Int J Chron Obstruct Pulmon Dis. 2016 Oct 19; 11: 2597-2607. DOl: https://doi.org/10.2147/COPD. S101382. eCollection 2016. PMID: 27799758.

25. Hurwitz J.L., Jones B. G., Penkert R. R., Gansebom S., Sun Y., Tang L. et al. Low Retinol-Binding Protein and Vitamin D Levels Are Associated with Severe Outcomes in Children Hospitalized with Lower Respiratory Tract Infection and Respiratory Syncytial Virus or Human Metapneumovirus Detection. J Pediatr. 2017; 187: 323-327. DOI: https://doi.org/10.1016/j.jpeds.2017.04.061.27.

26. Souto Filho J. T.D., de Andrade A. S., Ribeiro F. M., Alves P. A.S., Simonini V.R.F. Impact of vitamin $D$ deficiency on increased blood eosinophil counts. Hematol Oncol Stem Cell Ther. 2018 Mar; 11 (1): 25-29. DOl: https://doi.org/10.1016/j.hemonc.2017.06.003. Epub 2017 Aug 16. PMID: 28830802.

27. Emami A., Javanmardi F., Pirbonyeh N., Akbari A. Prevalence of Underlying Diseases in Hospitalized Patients with COVID-19: a Systematic Review and Meta-Analysis. Arch Acad Emerg Med. 2020 Mar 24; 8 (1): e35. eCollection 2020. PMID: 32232218.

28. Zhao Q., Meng M., Kumar R., Wu Y., Huang J., Lian N., Deng Y., Lin S. The impact of COPD and smoking history on the severity of Covid-19: A systemic review and meta-analysis. J Med Virol. 2020 Apr 15. DOI: https://doi.org/10.1002/jmv.25889. PMID: 32293753.

29. Xu J., Bartz T.M., Chittoor G., Eiriksdottir G., Manichaikul A.W., Sun F., Terzikhan N., Zhou X., Booth S.L., Brusselle G.G., de Boer I.H., Fornage M., Frazier-Wood A.C., Graff M., Gudnason V., Harris T.B., Hofman A., Hou R., Houston D.K., Jacobs D.R., Kritchevsky S.B., Latourelle J., Lemaitre R.N., Lutsey P.L., O'Connor G., Oelsner E.C., Pankow J.S., Psaty B. M., Rohde R. R., Rich S. S., Rotter J. I., Smith L. J., Stricker B.H., Voruganti V.S., Wang T.J., Zillikens M.C., Barr R.G., Dupuis J., Gharib S.A., Lahousse L., London S.J., $\quad$ North K.E.,
Smith A. V., Steffen L.M., Hancock D. B., Cassano P. A. Meta-analysis across Cohorts forHeart and Aging Research in Genomic Epidemiology (CHARGE) consortium providesevidence for an association of serum vitamin D with pulmonary function. Br JNutr. 2018 Nov; 120 (10): 1159 1170. DOI: https://doi.org/10.1017/S0007114518002180. PMID: 30205856 .

30. Liu C., Jiang Z. C., Shao C. X., Zhang H. G., Yue H. M., Chen Z. H., Ma B.Y., Liu W.Y., Huang H.H., Yang J., Wang Y., Liu H.Y., Xu D., Wang J.T., Yang J.Y., Pan H.Q., Zou S.Q., Li F.J., Lei J.Q., Li X., He Q., Gu Y., Qi X.L. Preliminary study of the relationship between novel coronavirus pneumonia and liver function damage: a multicenter study. Zhonghua Gan Zang Bing Za Zhi. 2020 Feb 20; 28 (2): 148-152. DOI: $\quad$ https://doi.org/10.3760/cma.j.issn.1007-3418.2020.02.003. PMID: 32077660.

31. Jin X., Lian J.S., Hu J.H., Gao J., Zheng L., Zhang Y.M., Hao S.R., Jia H.Y., Cai H., Zhang X. L., Yu G.D., Xu K. J., Wang X.Y., Gu J.Q., Zhang S.Y., Ye C.Y., Jin C.L., LuY.F., YuX., YuX.P., Huang J.R., Xu K.L., Ni Q., Yu C.B., Zhu B., Li Y.T., Liu J., Zhao H., Zhang X., Yu L., Guo Y.Z., Su J.W., Tao J.J., Lang G. J., Wu X.X., Wu W. R., Qv T. T., Xiang D. R., Yi P., Shi D., Chen Y., Ren Y., Qiu Y. Q., Li L.J., Sheng J., Yang Y. Epidemiological, clinical and virological characteristics of 74 cases of coronavirus-infected disease 2019 (COVID-19) with gastrointestinal symptoms. Gut. 2020 Mar 24; pii: gutjnl-2020-320926. DOl: https://doi.org/10.1136/gutjnl-2020-320926. PMID: 32213556.

32. Tang N., Li D., Wang X., Sun Z. Abnormal coagulation parameters are associated with poor prognosis in patients with novel coronavirus pneumonia. J Thromb Haemost. 2020 Apr; 18 (4): 844847. DOI: https://doi.org/10.1111/jth.14768. Epub 2020 Mar 13. PMID: 32073213.

33. Ji H.L., Zhao R., Matalon S., Matthay M.A. Elevated Plasmin(ogen) as a Common Risk Factor for COVID-19 Susceptibility. Physiol Rev. 2020 Jul 1; 100 (3): 1065-1075. DOl: https://doi.org/10.1152/physrev.00013.2020. Epub 2020 Mar 27. PMID: 32216698.

34. Wu J., Li W., Shi X., Chen Z., Jiang B., Liu J., Wang D., Liu C., Meng Y., Cui L., Yu J., Cao H., Li L. Early antiviral treatment contributes to alleviate the severity and improve the prognosis of patients with novel coronavirus disease (COVID-19). J Intern Med. 2020 Mar 27; DOI: https://doi.org/10.1111/joim.13063. PMID: 32220033.

35. Yang J., Zheng Y., Gou X., Pu K., Chen Z., Guo Q., Ji R., Wang H., Wang Y., Zhou Y. Prevalence of comorbidities and its effects in coronavirus disease 2019 patients: A systematic review and metaanalysis. Int J Infect Dis. 2020 Mar 12; 94: 91-95. D0I: https://doi. org/10.1016/j.ijid.2020.03.017. PMID: 32173574.

36. Madjid M., Safavi-Naeini P., Solomon S. D., Vardeny O. Potential Effects of Coronaviruses on the Cardiovascular System: A Review. JAMA Cardiol. 2020 Mar 27. pii: 2763846. DOI: https://doi.org/10.1001/ jamacardio.2020.1286. PMID: 32219363.

37. Ma W.X., Ran X.W. The Management of Blood Glucose Should be Emphasized in the Treatment of COVID-19. Sichuan Da Xue Xue Bao Yi Xue Ban. 2020 Mar; 51 (2): 146-150. DOl: https://doi. org/10.12182/20200360606. PMID: 32220179.

38. Satia M. C., Mukim A.G., Tibrewala K.D., Bhavsar M.S. A randomized two way cross over study for comparison of absorption of vitamin D3 buccal spray and soft gelatin capsule formulation in healthy subjects and in patients with intestinal malabsorption. Nutr J. 2015 Oct 29; 14: 114. DOl: https://doi.org/10.1186/s12937-015-0105-1. PubMed PMID: 26514332; PubMed Central PMCID: PMC4627615. 


\section{Сведения об авторах:}

Громова Ольга Алексеевна - д.м.н., профессор, в.н.с., научный руководитель Института фрармакоинформатики, ФИЦ «Информатика и Управление» PAH; в.н.с. Центра хранения и анализа больших данных, МГУ. Author ID: 94901; Scopus Author ID: 7003589812; 0RCID ID: https://orcid.org/0000-0002-7663710Х; WoS ResearcherID: J-4946-2017. РИНЦ SPIN-код: 6317-9833. E-mail: unesco.gromova@gmail.com.

Торшин Иван Юрьевич - к.ф-м.н., к.Х.Н., С.н.с., Институт фармакоинформатики, ФИЦ «Информатика и Управление» PAH. Scopus Аuthor ID: 7003300274; Author ID: 54104; ORCID ID: https://orcid.org/0000-0002-2659-7998; WoS ResearcherID: C-7683-2018. РИНЦ SPIN-код: $1375-1114$.

Габдулина Гульжан Хамзенична - к.м. н, профессор кафедры общей врачебной практики №1 НАО «Казахский национальный медицинский университет им. С.Д. Асфендиярова».

\section{About the authors:}

Olga A. Gromova - MD, Dr Sci Med, Professor, Senior Researcher, Scientific Director of the Federal Research Center "Informatics and Management", Russian Academy of Sciences; Leading Researcher, Center for Big Data Analysis, Moscow State University; Author ID: 94901; Scopus Author ID: 7003589812; ORCID ID: https://orcid.org/0000-0002-7663-710X; WoS ResearcherID: J-4946-2017. RSCI SPIN-code: 6317-9833. E-mail: unesco.gromova@gmail.com.

Ivan Yu. Torshin - MD, PhD, Senior Researcher, Federal Research Center "Informatics and Management", Russian Academy of Sciences; Big Data Storage and Analysis Center, Moscow State University. Scopus Author ID: 7003300274; Author ID: 54104; ORCID ID: https://orcid.org/0000-0002-2659-7998; WoS ResearcherID: C-7683-2018. RSCI SPIN-code: 1375-1114.

Gulzhan Kh. Gabdulina - MD, PhD, Professor, Department of General Medical Practice No. 1, Kazakh National Medical University S. D. Asfendiyarova. 